\title{
PI3K $\alpha$ inactivation in leptin receptor cells increases leptin sensitivity but disrupts growth and reproduction
}

\author{
David Garcia-Galiano, ${ }^{1}$ Beatriz C. Borges, ${ }^{1,2}$ Jose Donato Jr., ${ }^{3}$ Susan J. Allen, ${ }^{1}$ Nicole Bellefontaine, ${ }^{1}$ \\ Mengjie Wang, ${ }^{4}$ Jean J. Zhao, ${ }^{5}$ Kenneth M. Kozloff, ${ }^{6}$ Jennifer W. Hill, ${ }^{4}$ and Carol F. Elias ${ }^{1,7}$ \\ 'Department of Molecular and Integrative Physiology, University of Michigan, Ann Arbor, Michigan, USA. 'Department \\ of Physiology and ${ }^{3}$ Department of Physiology and Biophysics, University of São Paulo, São Paulo, Brazil. ${ }^{4}$ Department of \\ Physiology and Pharmacology, University of Toledo, Toledo, Ohio, USA. ${ }^{5}$ Department of Biological Chemistry and Molecular \\ Pharmacology, Harvard Medical School, Boston, Massachusetts, USA. ${ }^{6}$ Department of Biomedical Engineering and \\ ${ }^{7}$ Department of Obstetrics and Gynecology, University of Michigan, Ann Arbor, Michigan, USA.
}

\begin{abstract}
The role of PI3K in leptin physiology has been difficult to determine due to its actions downstream of several metabolic cues, including insulin. Here, we used a series of mouse models to dissociate the roles of specific PI3K catalytic subunits and of insulin receptor (InsR) downstream of leptin signaling. We show that disruption of $p 110 \alpha$ and $p 110 \beta$ subunits in leptin receptor cells (LR ${ }^{\Delta \alpha+\beta}$ ) produces a lean phenotype associated with increased energy expenditure, locomotor activity, and thermogenesis. $\operatorname{LR}^{\Delta \alpha+\beta}$ mice have deficient growth and delayed puberty. Single subunit deletion (i.e., p110 $\alpha$ in $\mathrm{LR}^{\Delta \alpha}$ ) resulted in similarly increased energy expenditure, deficient growth, and pubertal development, but $\mathrm{LR}^{\Delta a}$ mice have normal locomotor activity and thermogenesis. Blunted PI3K in leptin receptor (LR) cells enhanced leptin sensitivity in metabolic regulation due to increased basal hypothalamic PAKT, leptin-induced pSTAT3, and decreased PTEN levels. However, these mice are unresponsive to leptin's effects on growth and puberty. We further assessed if these phenotypes were associated with disruption of insulin signaling. $\mathrm{LR}^{\mathrm{\Lambda nsR}}$ mice have no metabolic or growth deficit and show only mild delay in pubertal completion. Our findings demonstrate that PI3K in LR cells plays an essential role in energy expenditure, growth, and reproduction. These actions are independent from insulin signaling.
\end{abstract}

Conflict of interest: The authors have declared that no conflict of interest exists.

Submitted: August 7, 2017 Accepted: October 23, 2017 Published: December 7, 2017

Reference information: JCI Insight. 2017;2(23):e96728. https://doi.org/10.1172/jici. insight.96728.

\section{Introduction}

Epidemiological and genetic studies have determined the existence of a close link between metabolic dysfunction (e.g., obesity and diabetes) and many types of cancer. Phosphatidylinositol 3-kinase (PI3K) signaling is the major molecular pathway associated with these diseases and comorbidities (1-3). It plays a key role in the central actions of metabolic cues and growth factors in energy balance, glucose homeostasis, and cellular growth (4-8). Among the multiple PI3K isoforms, those pertaining to class IA are responsive to metabolic signals (9). The $\mathrm{p} 110 \alpha(\mathrm{PI} 3 \mathrm{~K} \alpha)$ and $\mathrm{p} 110 \beta(\mathrm{PI} 3 \mathrm{~K} \beta)$ catalytic subunits are ubiquitously expressed, and whole-body knockout of either PI3K $\alpha$ or PI3K $\beta$ subunit is embryonically lethal $(1,10)$. Mice carrying mutations with reduced activity of PI3K $\alpha$ display decreased body weight and body length (1). Over the long term, these physiological adaptations are translated into beneficial effects on metabolic regulation and aging (11-13). However, enhanced PI3K signaling only in cells that express leptin receptor (LR) due to cell-type-specific deletion of phosphatase and tensin homolog (PTEN; $\mathrm{LR}^{\triangle \mathrm{PTEN}}$ mice) generates mice with a metabolic phenotype similar to those with reduced global PI3K activity, i.e., decreased adiposity and increased energy expenditure (14).

The use of conditional deletion of PI3K in chemically defined hypothalamic neurons has contributed to the advancement of the field, but findings showing that leptin and insulin act in distinct neuronal populations represent an obvious confounder. For example, subsets of proopiomelanocortin (POMC) and steroidogenesis factor 1 (SF1) neurons are responsive to either leptin or insulin (15-19), and, therefore, it is not entirely known if the phenotype of mice with PI3K deletion in those neurons is due to lack of leptin or insulin signaling. Conditional deletion of PI3K $\alpha$ or PI3K $\beta$ in POMC and SF1 
neurons has suggested the existence of dissociated effects of both subunits in energy balance and glucose homeostasis $(16,20-22)$, but, again, whether these responses are associated with leptin or insulin signaling has not been demonstrated.

Selective mutations in LR tyrosine residues have produced compelling data on the effects of specific signaling pathways in leptin function (23-25). Mice with blockade of LR-activated STAT3 signaling are obese and have disrupted thyroid and adrenal axes. However, they show improved glucose homeostasis, growth, and fertility compared with leptin signaling-deficient $\left(d b / d b, L e p r^{d b}\right)$ mice. Likewise, lack of either leptin-induced SHP2/ERK or STAT5 pathways caused only mild metabolic and neuroendocrine phenotypes (24-26). Here, we used single and dual deletion of PI3K $\alpha$ and PI3K $\beta$ in LR cells to dissect the role of individual PI3K catalytic subunits in energy homeostasis, growth, and reproductive function. We further assessed if the observed phenotypes were associated with convergent insulin signaling in LR cells.

\section{Results}

Mice with deletion of PI3K signaling pathway in LR cells have disrupted energy homeostasis, growth, and sexual maturation. Mice lacking both PI3K $\alpha$ and PI3K $\beta$ catalytic subunits in LR cells (LR ${ }^{\Delta \alpha+\beta}$ mice) were generated and validated in previous electrophysiological studies from our laboratory $(17,27)$. Deletion of both subunits disrupts the acute effects of leptin and insulin in resting membrane potential of hypothalamic LR neurons $(6,17)$. However, the physiological consequences of this manipulation have not been determined. Male and female $\mathrm{LR}^{\Delta \alpha+\beta}$ mice showed decreased body weight compared with floxed control mice ( $\alpha^{\mathrm{fl}}+\beta^{\mathrm{fl}}$; Figure $\left.1 \mathrm{~A}\right)$. Reduced lean and fat mass associated with a decrease in body length was evident in adult $\mathrm{LR}^{\Delta \alpha+\beta}$ mice compared with age-matched controls (Figure 1, B and C). The $\alpha^{\mathrm{fl}}+\beta^{\mathrm{fl}}$ mice and those homozygous for LepR-Cre ( $\mathrm{LR}^{\text {cre/cre }}$ mice) showed no differences in body weight or body length (Supplemental Figure 1, A and B; supplemental material available online with this article; https://doi.org/10.1172/jci.insight.96728DS1). The $\mathrm{LR}^{\Delta \alpha+\beta}$ mice consumed the same amount of food compared with controls (Supplemental Figure 1C) but had increased daily food intake when normalized to body weight (Figure 1D). They also displayed higher energy expenditure in both light and dark phases, determined by increased $\mathrm{O}_{2}$ consumption and $\mathrm{CO}_{2}$ production, and no changes in respiratory exchange ratio (RER; Figure 1, E and F, and Supplemental Figure 1, D-F). $L^{\Delta \alpha+\beta}$ mice have increased uncoupling protein 1 (Ucp1) mRNA expression in brown adipose tissue (BAT) and increased locomotor activity in both light and dark phases (Figure 1, G-I). No changes in fasted glucose levels, glucose, or insulin tolerances were observed (Figure 1, J-L). However, $\mathrm{LR}^{\Delta \alpha+\beta}$ mice showed reduced insulin levels in fasted conditions compared with control mice.

Reproductive function and metabolic status are tightly linked $(28,29)$. Puberty onset (vaginal opening) and completion (first estrus) were both delayed in $\mathrm{LR}^{\Delta \alpha+\beta}$ mice (Figure $1, \mathrm{M}$ and $\mathrm{N}$ ); $25 \%$ of $\mathrm{LR}^{\Delta \alpha+\beta}$ females showed no first estrus until P60. However, no differences in estrous cycle length or fertility were noticed in adult (3- to 5-month-old) LR ${ }^{\Delta \alpha+\beta}$ mice (Figure $1 O$ and Supplemental Figure 1, G and H). In males, no differences in age of puberty onset, revealed by the day of balanopreputial separation, were detected in $L^{\Delta a+\beta}$ mice, although adult $\mathrm{LR}^{\Delta \alpha+\beta}$ males had reduced testis weight. Epididymis weight and circulating luteinizing hormone (LH) levels did not differ from those of controls (Supplemental Figure 1, I-L).

$P I 3 K \alpha$ in LR cells is required for normal food intake, energy expenditure, and growth. To dissociate the roles of PI3K catalytic subunits, we generated mice with single subunit deletion (PI3K $\alpha$ ) in LR cells (LR ${ }^{\Delta \alpha}$ ). Deletion of the Pik3ca gene (coding the PI3K $\alpha$ subunit) was confirmed by quantitative PCR (qPCR) analysis in hypothalamic blocks, in the arcuate nucleus (Arc) punches, and in LR cells expressing tdTomato reporter gene harvested by FACS. Double ISH/IHC in hypothalamic sections of LR ${ }^{\text {cre/cre }}$ tdTomato control and mutant mice also showed successful deletion of Pik3ca gene in LR cells (Supplemental Figure 2, A-D).

Similar to $\mathrm{LR}^{\Delta \alpha+\beta}$ mice, $\mathrm{LR}^{\Delta \alpha}$ males and females displayed lower body weight, a reduction in lean and fat mass, and reduced growth (snout-anus distance) compared with control $\alpha^{\mathrm{fl}}$ mice (Figure 2, A-C). No differences in body weight or body length were observed comparing $\alpha^{\mathrm{fl}}$ males and LR ${ }^{\text {cre/cre }}$ mice (Supplemental Figure 3 , $\mathrm{A}$ and $\mathrm{B})$. Male $\mathrm{LR}^{\Delta \alpha}$ mice also displayed a significant increase in food intake when normalized to body weight, and increased energy expenditure due to increased $\mathrm{O}_{2}$ consumption and $\mathrm{CO}_{2}$ production, in both dark and light phases (Figure 2, D-F, and Supplemental Figure 3, C-E). No changes in RER, fasted glucose levels, or glucose tolerance were observed (Supplemental Figure 3, F-H). In contrast to LR ${ }^{\Delta \alpha+\beta}$ mice, BAT Ucp1 mRNA expression, locomotor activity, and fasted insulin levels were not different in $\mathrm{LR}^{\Delta \alpha}$ mice (Figure 2, G-J).

To gain insights into the cellular mechanisms associated with the phenotype of the PI3K $\alpha$ deletion, we assessed changes in gene expression in Arc punches from adult males. No changes in POMC or neuro- 

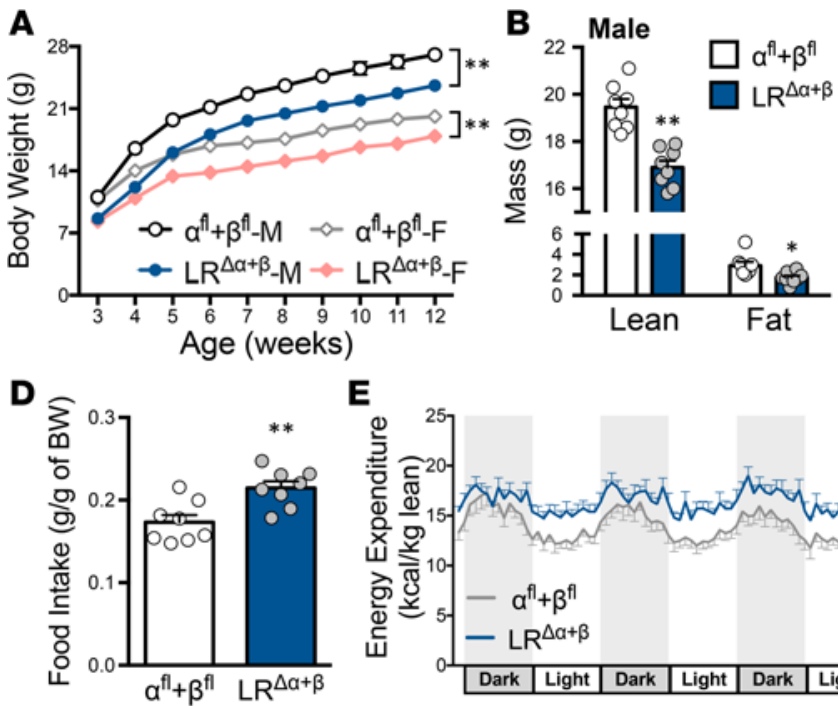

E
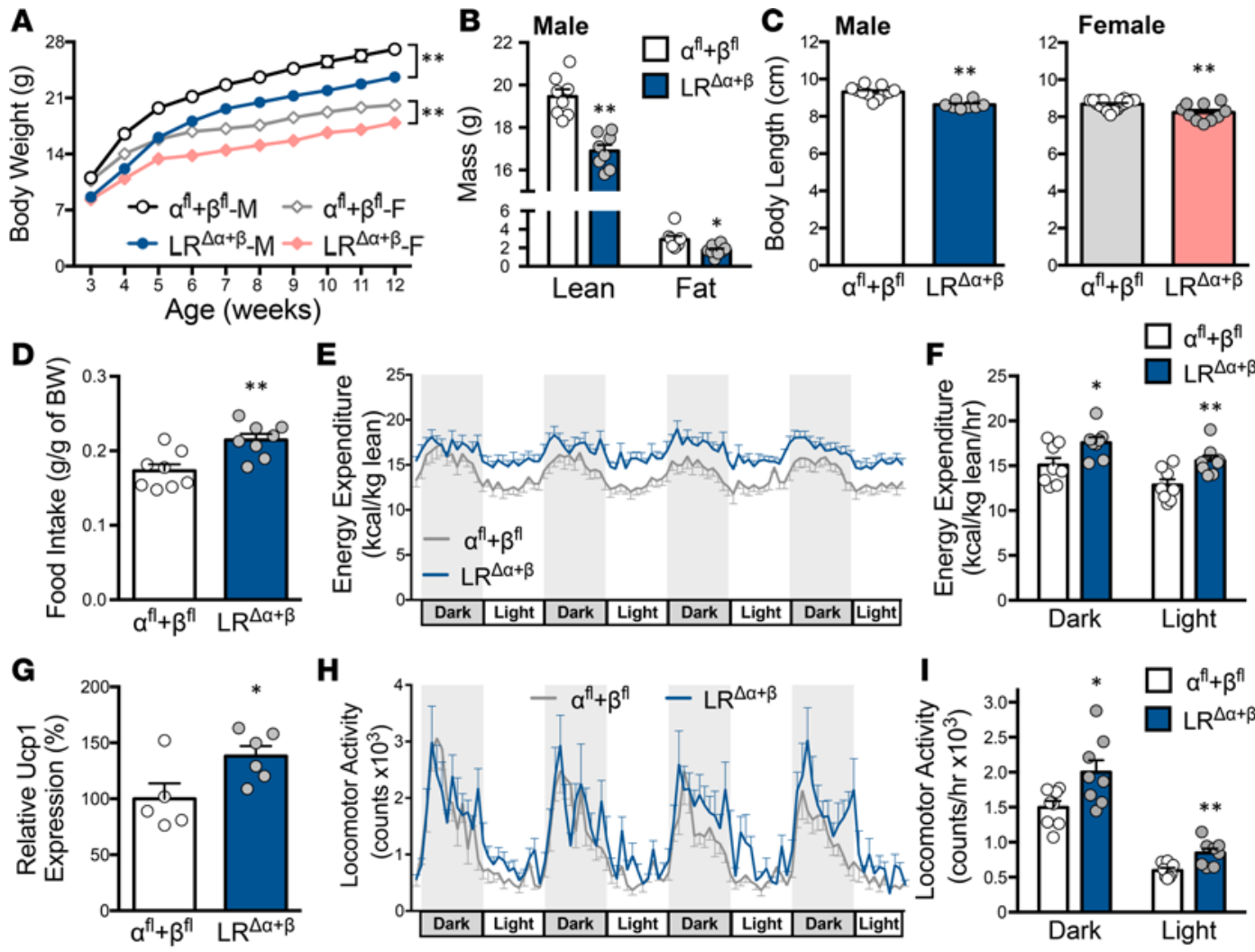

H
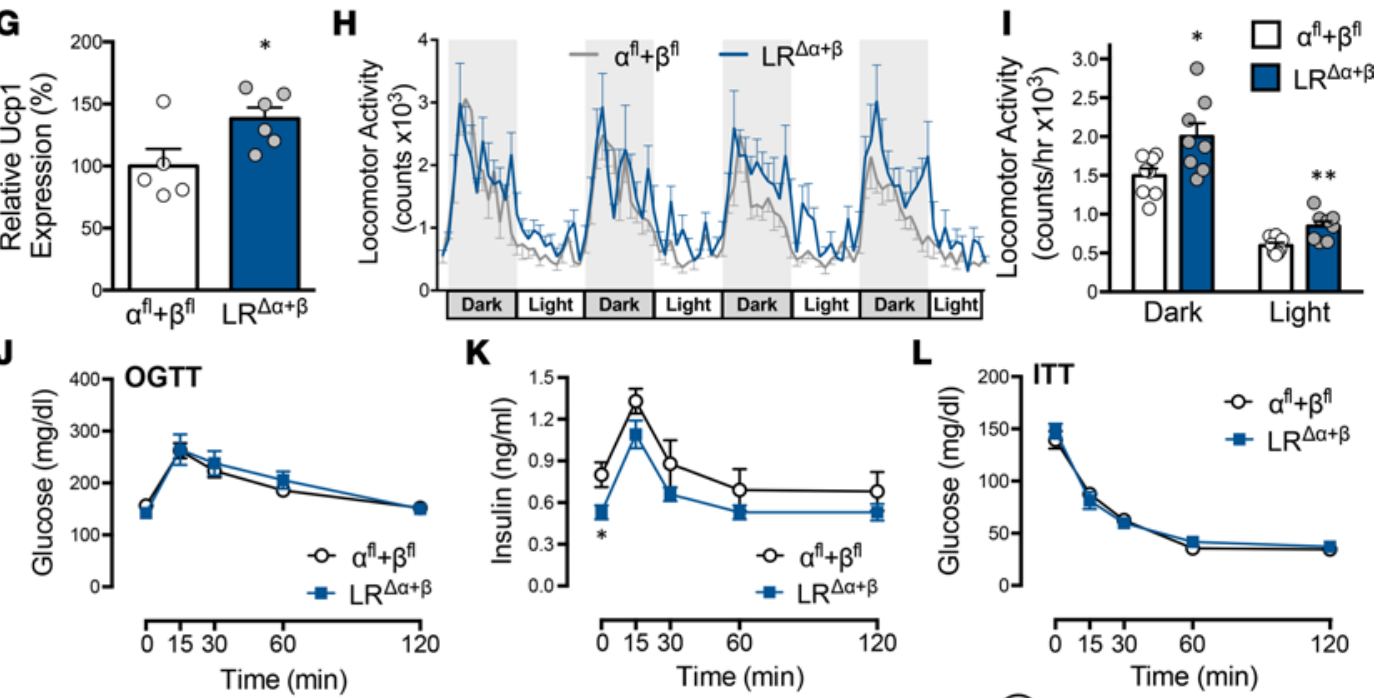

$\mathbf{K}$
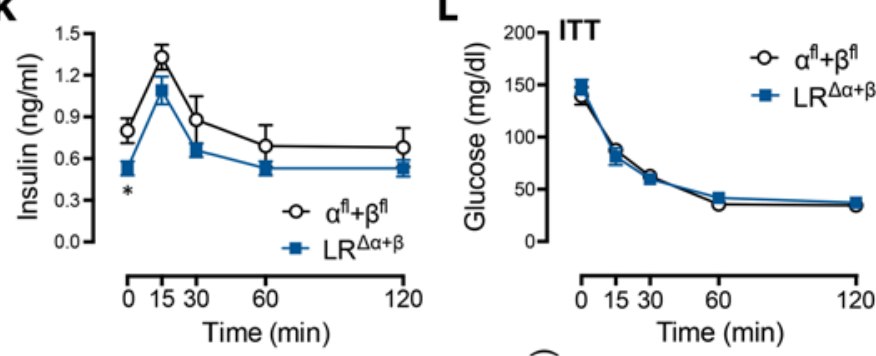

M
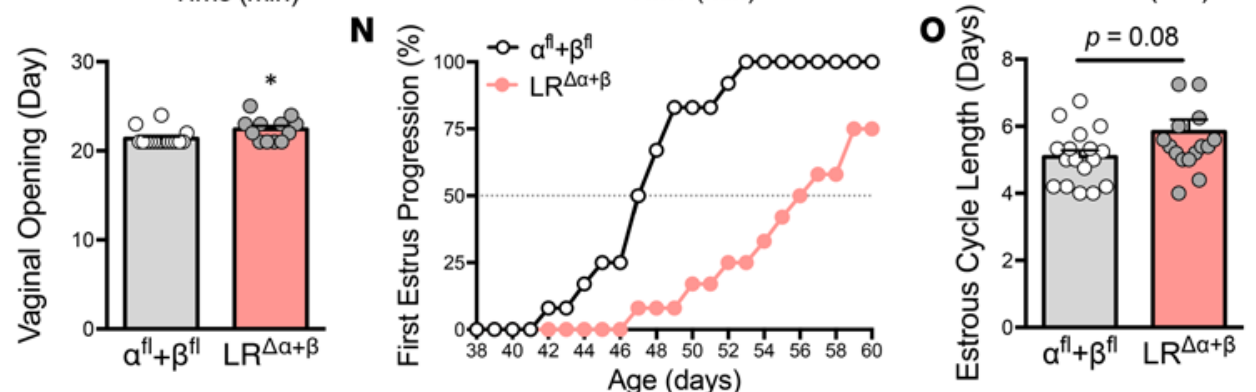

Figure 1. Deletion of PI3K $\alpha$ and PI3K $\beta$ in LR cells causes changes in energy expenditure, growth, and puberty. (A) Reduced body weight in male (M) $\operatorname{LR}^{\Delta \alpha+\beta}(n=13)$ versus $\alpha^{f 1}+\beta^{f l}[n=21 ; F(1,32)=19.67, P<0.0001]$ mice and in female $(F) \operatorname{LR}^{\Delta \alpha+\beta}(n=13)$ versus $\alpha^{f l}+\beta^{f l}[n=16 ; F(1,27)=28.37, P<0.0001]$ mice from 2 independent cohorts. (B) Reduced body composition in $\mathrm{LR}^{\Delta \alpha+\beta}$ mice $\left(n=8 /\right.$ group, males; $t_{14}=5.83, P<0.0001$ for lean mass; $t_{14}=2.81, P$ $=0.014$ for fat mass). (C) Reduced body length at 9 weeks of age, in male $\operatorname{LR}^{\Delta \alpha+\beta}(n=8)$ versus $\alpha^{f 1}+\beta^{f 1}\left(n=11 ; t_{17}=5.28, P<0.0001\right)$ mice and in female $\operatorname{LR}^{\Delta \alpha+\beta}(n=10)$ versus $\alpha^{f l}+\beta^{f l}\left(n=18 ; t_{17}=5.28, P=0.002\right)$ mice. (D-F) CLAMS study ( $n=8 /$ group, males) detected differences in (D) 24 -hour food intake normalized to body weight $\left(t_{14}=5.83, P<0.0001\right)$, (E) in 4-day energy expenditure, and $(\mathbf{F})$ averages for dark and light phases in LR $\mathrm{R}^{\Delta \alpha+\beta}$ versus $\alpha^{\mathrm{fl}}+\beta^{\mathrm{fl}}$ mice $\left(t_{14}=2.56, P=0.024\right.$ for dark phase; $t_{14}=3.19, P=0.006$ for light phase). (G) Increased BAT Ucp1 mRNA in adult male LR ${ }^{\Delta \alpha+\beta}(n=6)$ versus $\alpha^{f 1}+\beta^{f l}$ ( $\left.n=5 ; t_{9}=2.41, P=0.04\right)$ mice. (H) Increased locomotor activity (4 days, $n=8 /$ group) and (I) averages for dark and light phases in male LR ${ }^{\Delta a+\beta}\left(t_{14}=\right.$ 2.6, $P=0.021$ for dark phase; $t_{14}=3.42, P=0.004$ for light phase) mice. (J) Glucose and (K) insulin levels in oral glucose tolerance test (OCTT; $t_{12}=2.62$, $P=0.02$ at basal levels compared with $\left.\alpha^{\mathrm{fl}}+\beta^{\mathrm{fl}}\right)$, or circulating glucose in insulin tolerance test (ITT, L) at basal $(0$ minutes), 15, 30, 60, and 120 minutes after oral glucose ( $n=7 /$ group, males). (M) Delayed vaginal opening in $\operatorname{LR}^{\Delta \alpha+\beta}(n=12)$ versus $\alpha^{f 1}+\beta^{f f}\left(n=16 ; t_{26}=2.51, P=0.019\right)$ mice and $(\mathbf{N})$ first estrus in $\operatorname{LR}^{\Delta \alpha+\beta}(n=13)$ versus $\alpha^{f 1}+\beta^{f l}(n=12)$ mice. (0) Normal estrous cycle length in $\operatorname{LR}^{\Delta \alpha+\beta}(n=16)$ versus $\alpha^{f 1}+\beta^{f \mid}\left(n=17 ; t_{31}=1.81, P=0.08\right)$ mice. Circles in bar graphs represent individual mice. Values are presented as mean $\pm \mathrm{SEM}$. ${ }^{*} P<0.05$, ${ }^{* *} P<0.01$, by repeated-measures 2 -way ANOVA with Holm-Sidak's multiple comparisons (A) and by 2-tailed Student's $t$ test (B-O). LR ${ }^{\Delta \alpha+\beta}$, deletion of PI3K $\alpha$ and PI3K $\beta$ in LR cells. 
peptide Y (NPY) mRNA levels were detected, but a significant increase in agouti-related peptide (AgRP) transcript was observed in $\mathrm{LR}^{\Delta \alpha}$ mice. We also observed a higher density of AgRP-immunoreactive fibers in the paraventricular nucleus of the hypothalamus $(\mathrm{PVH})$ in fed $\mathrm{LR}^{\Delta \alpha}$ mice. Overnight fasted $\alpha^{\mathrm{fl}}$ and $\mathrm{LR}^{\Delta \alpha}$ mice displayed similar density of PVH AgRP fibers (Figure 2, K-M). Together, these findings suggest that deletion of PI3Ka generates a condition of perceived negative energy balance in AgRP neurons.

$P I 3 K \alpha$ in LR cells is necessary for pubertal development, estrous cycle, and fertility. Timing of puberty onset, observed by age of vaginal opening and balanopreputial separation, was similar in $\mathrm{LR}^{\Delta \alpha}$ and control $\alpha^{\mathrm{f}}$ mice (Figure 3A and Supplemental Figure 3I). However, LR ${ }^{\Delta \alpha}$ females showed a delay for pubertal completion, defined by age of first estrus, compared with controls (Figure 3B). No differences in sexual maturation, testis, or epididymis weight were noticed in $\mathrm{LR}^{\Delta \alpha}$ males (Supplemental Figure 3, J-L).

To assess whether the delayed pubertal maturation detected in $\mathrm{LR}^{\Delta \alpha}$ mice is secondary to the reduced body weight, we performed an early postnatal overnutrition paradigm to increase their body weight (28, 30,31 ). At weaning day (at 3 weeks of age), $L^{\Delta a}$ females from small litters (LR ${ }^{\Delta a}$-SL mice) had body weight similar to controls from normal litters ( $\alpha^{\mathrm{fl}}-\mathrm{NL}$ mice; Figure $3 \mathrm{C}$ ). After 2 weeks, body weight of $\mathrm{LR}^{\Delta \alpha}$ SL females was diminished compared with $\alpha^{\mathrm{fl}}-\mathrm{NL}$ mice but increased compared with $\mathrm{LR}^{\Delta \alpha}-\mathrm{NL}$ females. Notably, at P40, leptin levels were reduced in $\mathrm{LR}^{\Delta \alpha}-\mathrm{NL}$ mice compared with $\alpha^{\mathrm{fl}}$-NL females, but they were not different compared with LR ${ }^{\Delta \alpha}$-SL mice (Figure 3D). No differences in LH levels were detected among groups, but ovary weight was reduced in $\mathrm{LR}^{\Delta \alpha}$ mice (NL and SL) compared with age-matched controls (Figure 3, E and F). Early feeding manipulation in LR ${ }^{\Delta a}-\mathrm{SL}$ females improved but did not normalize the timing of pubertal completion. Remarkably, whereas most (about $80 \%$ ) of control mice displayed pubertal completion at 6 weeks of age (around P40), only about $25 \%$ of $\mathrm{LR}^{\Delta \alpha}-\mathrm{NL}$ and $\mathrm{LR}^{\Delta \alpha}$-SL mice were at the same developmental stage at P40 (Figure 3, G and $\mathrm{H}$ ).

Because nutritional manipulation improved but did not correct body weight, leptin levels, and pubertal progression, we further assessed if decreased leptin levels could account for the delayed sexual maturation of $\mathrm{LR}^{\Delta \alpha}$ mice (29). Daily leptin administration to peripubertal $\alpha^{\mathrm{fl}}$ females decreased cumulative weight gain and advanced sexual maturation (Figure 3I and Supplemental Figure 4, A and B). Leptin supplementation to $\mathrm{LR}^{\Delta \alpha}$ females had an enhanced effect in weight loss but caused no changes in timing of pubertal development. Collectively, these data suggest that $\mathrm{LR}^{\Delta \alpha}$ mice have increased leptin sensitivity for body weight regulation but are unresponsive to leptin's effect in pubertal maturation.

Adult $\mathrm{LR}^{\Delta \alpha}$ females also displayed prolonged estrous cycles, reduced ovarian weight, and decreased ovulatory events (measured by number of days in proestrus; Figure 4, A-D). The reproductive deficit observed in $\mathrm{LR}^{\Delta a}$ females was associated with a progressive subfertility, as reduced numbers of pups were delivered in subsequent litters (Figure 4E). No alterations in timing of sexual maturation or estrous cycle length were observed in control homozygous $\mathrm{LR}^{\text {cre/cre }}$ mice (Supplemental Figure 5, A and B).

$L R^{\Delta \alpha}$ females are resistant to changes in reproductive function induced by metabolic manipulations and pregnan$c y$. To assess if the prolonged estrous cycles are secondary to decreased energy stores, adult $\mathrm{LR}^{\Delta \alpha}$ females were fed with a high-fat diet (HFD, 42\% fat). Following 7 weeks on HFD, both $\mathrm{LR}^{\Delta \alpha}$ and $\alpha^{\mathrm{fl}}$ mice showed increases in body weight and fat mass, although the effect was diminished in $\mathrm{LR}^{\Delta \alpha}$ females (Figure $4, \mathrm{~F}$ and G). At 7 weeks on HFD, when $\mathrm{LR}^{\Delta \alpha}$ females achieved similar body weight to $\alpha^{\mathrm{fl}}$ controls on regular chow diet (Supplemental Figure 5C), estrous cycles were monitored for another 7 weeks. The increase in body weight did not restore normal cyclicity in $\mathrm{LR}^{\Delta \alpha}$ females, but it induced longer estrous cycles in control $\alpha^{\mathrm{f}}$ mice (Figure 4H), as demonstrated previously in wild-type mice (32).

Fertility eventually returns after a period of suckling-induced anovulation during lactation (33, 34). We assessed the estrous cyclicity in $\mathrm{LR}^{\Delta \alpha}$ mice and controls on regular chow after pregnancy and lactation. Gestation and lactation did not normalize the body weight or body length of LR ${ }^{\Delta a}$ dams (Figure $4, \mathrm{I}$ and J). No restoration or improvement in estrous cycle length was detected in $\mathrm{LR}^{\Delta a}$ mice compared with $\alpha^{\mathrm{fl}}$ dams after a period of lactational amenorrhea (Figure $4 \mathrm{~K}$ ).

$P I 3 K \alpha$ expression in LR cells is required for growth. Reduced growth was only detected in sexually mature $\mathrm{LR}^{\Delta a}$ mice (at P60), with no differences observed in pubertal (P40) mice (Figure 5A). Analysis of gene expression at different levels of the growth axis showed no differences in hypothalamic growth hormonereleasing hormone $(\mathrm{GHRH})$ or somatostatin (SST) and pituitary growth hormone $(\mathrm{GH})$ or $\mathrm{GH}$ receptor (GHR) mRNA levels between genotypes at P60 (Figure 5B). A reduction in hepatic Ghr and Igf1 but no changes in Fgf21 expression were detected in adult $\mathrm{LR}^{\Delta \alpha}$ females. However, circulating levels of IGF1 were not different comparing pubertal or adult mice of both genotypes (Figure 5C). 

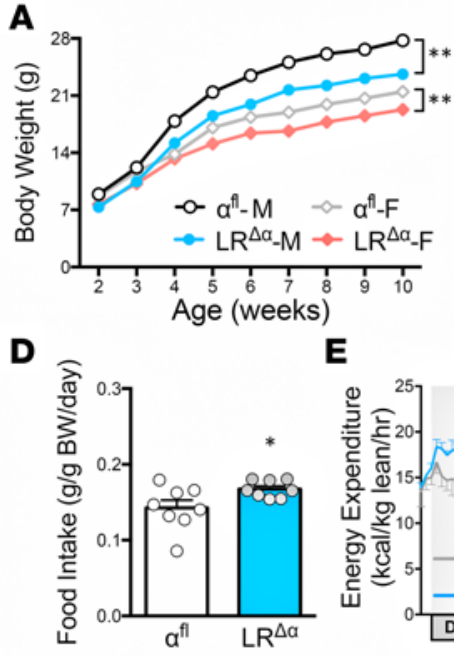

G

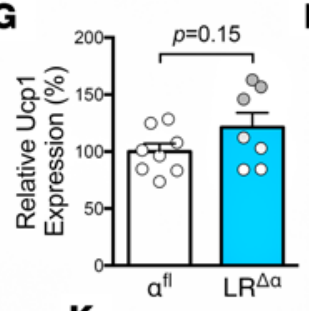

K

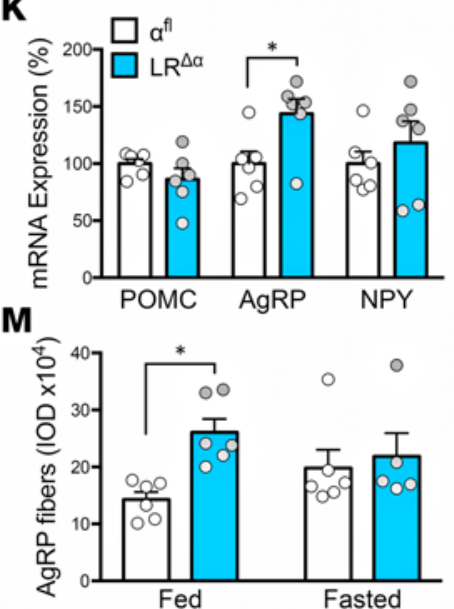

\section{E}
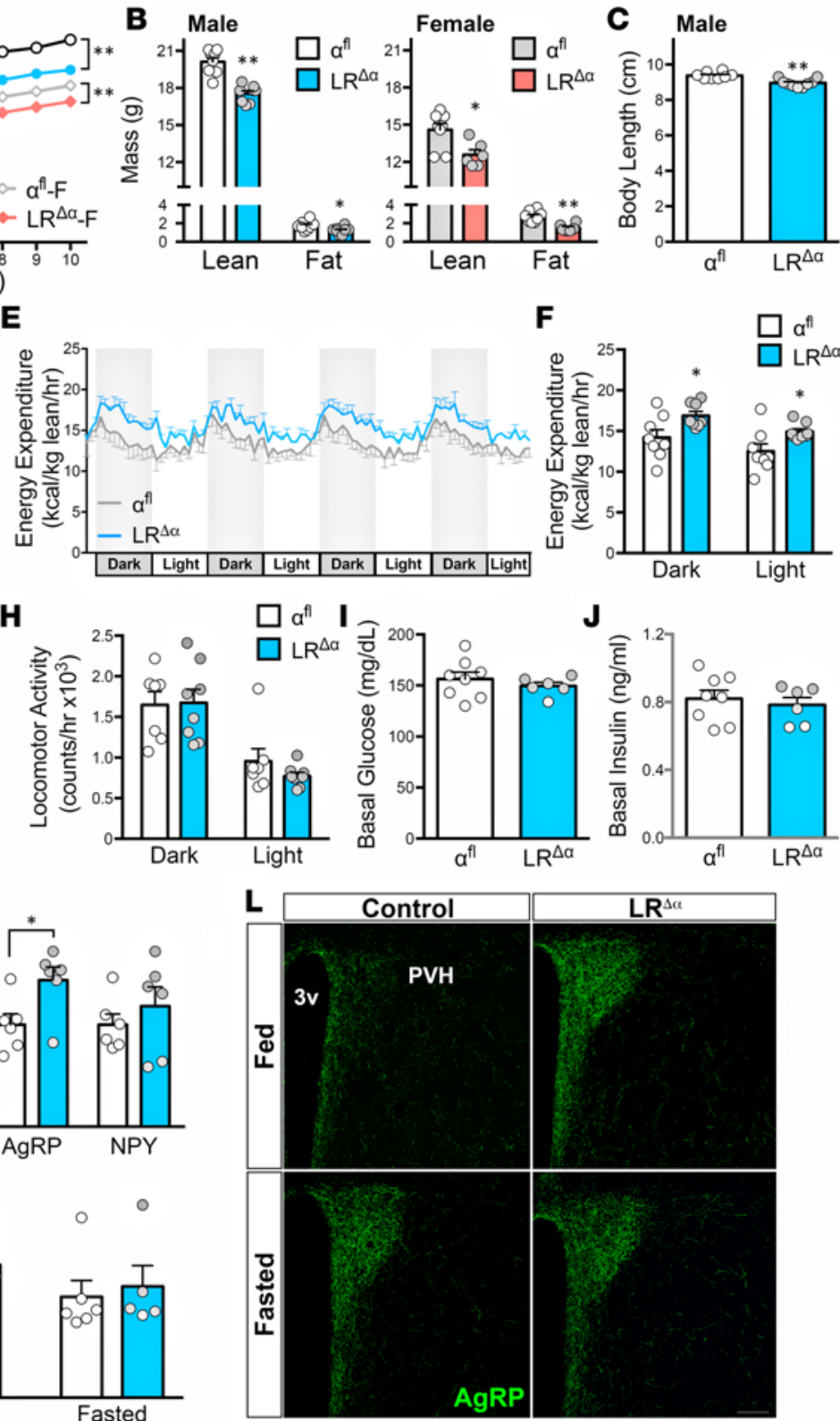

Figure 2. PI3K $\alpha$-deleted mice showed changes in food intake, energy expenditure, and growth but comparable locomotor activity and thermogenesis. (A) Reduced body weight in male $(M) \operatorname{LR}^{\Delta \alpha}(n=12)$ compared with $\alpha^{\mathrm{fl}}$ mice $[n=29 ; F(1,32)=22.78, P<0.0001]$ and in female $(\mathrm{F}) \mathrm{LR}{ }^{\Delta \alpha}(n=18)$ versus $\alpha^{\mathrm{fl}}$ mice $[n=31$; $F(1,47)=26.1, P<0.0001$ ] from 2 independent cohorts. (B) Reduced body composition in LR ${ }^{\Delta \alpha}$ mice $\left(n=8 /\right.$ group, males; $t_{14}=6.05, P<0.0001$ for lean mass; $t_{14}=$ 2.36, $P=0.033$ for fat mass) and in $\mathrm{LR}^{\Delta \alpha}(n=6)$ versus control female mice $\left(\alpha^{\mathrm{fl}}, n=8 ; t_{12}=2.91, P=0.013\right.$ for lean mass; $t_{14}=4.2, P=0.001$ for fat mass). (C) Reduced body length at 9 weeks of age in $\operatorname{LR}^{\Delta \alpha}(n=9)$ compared with $\alpha^{f l}$ male mice $\left(n=8 ; t_{15}=4.5, P=0.0004\right)$. CLAMS study (4 days, $n=8 /$ group, males) detected differences in daily normalized food intake ( $\left.\mathbf{D} ; t_{9.06}=2.26, P=0.05\right)$, (E) in 4-day energy expenditure, and $(\mathbf{F})$ averages for dark and light phases $\left(t_{14}=2.47, P=0.027\right.$ for dark phase; $t_{14}=2.45, P=0.028$ for light phase) in LR ${ }^{\Delta \alpha}$ compared with $\alpha^{\mathrm{fl}}$ mice but not in (H) locomotor activity. (G) Relative BAT Ucp1 mRNA expression in LR ${ }^{\alpha}(n=7)$ compared with $\alpha^{f \mid}$ male mice $\left(n=8 ; t_{13}=1.53, P=0.15\right)$. (I) Glucose and (J) insulin levels in fasted $\alpha^{f 1}(n=8)$ and LR ${ }^{\Delta \alpha}(n=6)$ male mice. (K) Arc Pomc, Agrp, and Npy expression in fed conditions ( $n=6$ /group; $t_{10}=2.62, P=0.026$ for AgRP expression). ( $\mathbf{L}$ and $\mathbf{M}$ ) Representative confocal images of AgRP fibers in the paraventricular nucleus of the hypothalamus (PVH) and integrated optic density (IOD) showed high AgRP fiber density in diestrus LR ${ }^{\Delta \alpha}$ mice with respect to controls in fed $[F(1,19)=6.09, P=0.023]$, but no difference in fasted conditions. Each point represents 1 individual mouse, and all values are presented as mean $\pm \mathrm{SEM}$. ${ }^{*} P<0.05$, ${ }^{*} P<0.01$, by repeated-measures 2-way ANOVA with Holm-Sidak's multiple comparisons test in A, by 2-way ANOVA with Tukey's post-hoc analysis in M, and 2-tailed Student's $t$ test in B-K. Scale bar: $100 \mu \mathrm{m}$. LR ${ }^{\Delta \alpha}$, PI3K $\alpha$-deleted mice.

The bone mineral density of the trabecular and cortical layers of the femur were decreased in $\mathrm{LR}^{\Delta a}$ females (P60). No changes in marrow area or total area were observed (Figure 5, D-N). Trabecular number and spacing were similar to those of controls, but trabecular thickness and bone volume were reduced. In lumbar vertebrae, no differences in bone volume, thickness, trabecular number, and spac- 
A

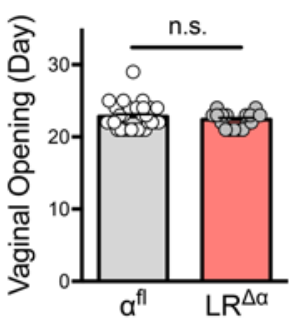

B

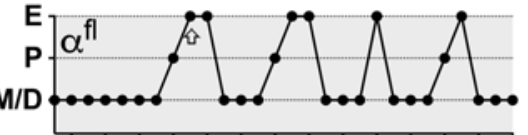

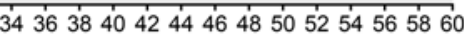

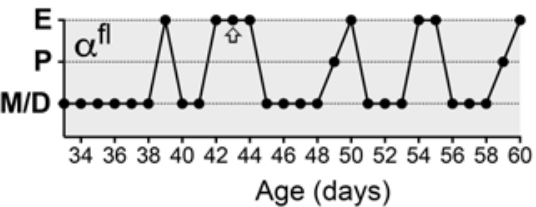

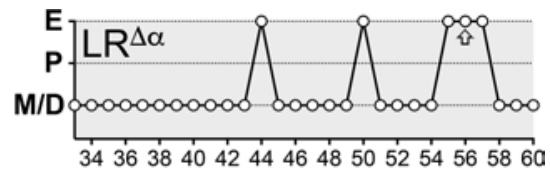

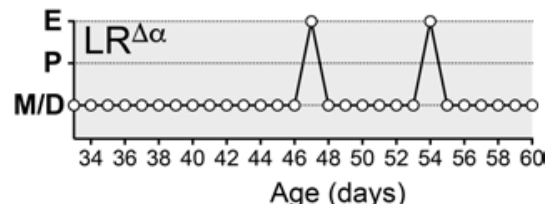

E

C

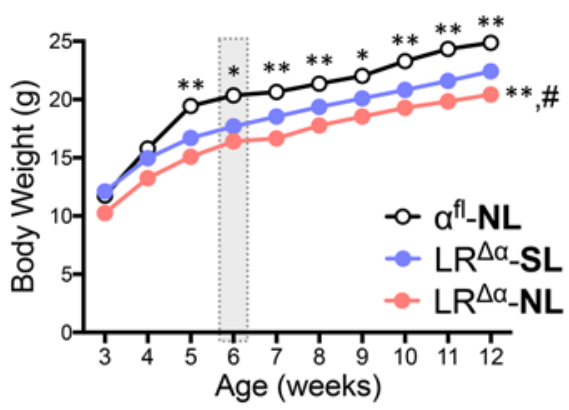

D
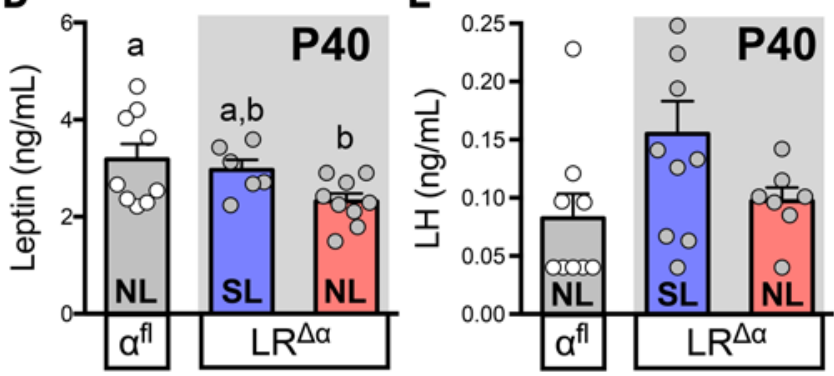

$\mathbf{F}$

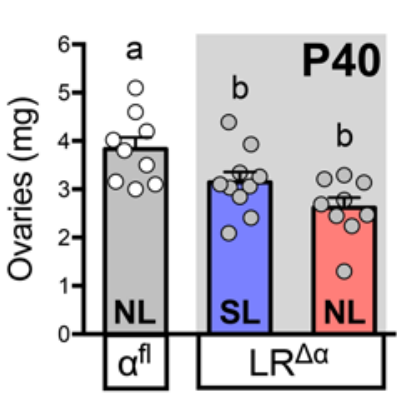

G 응
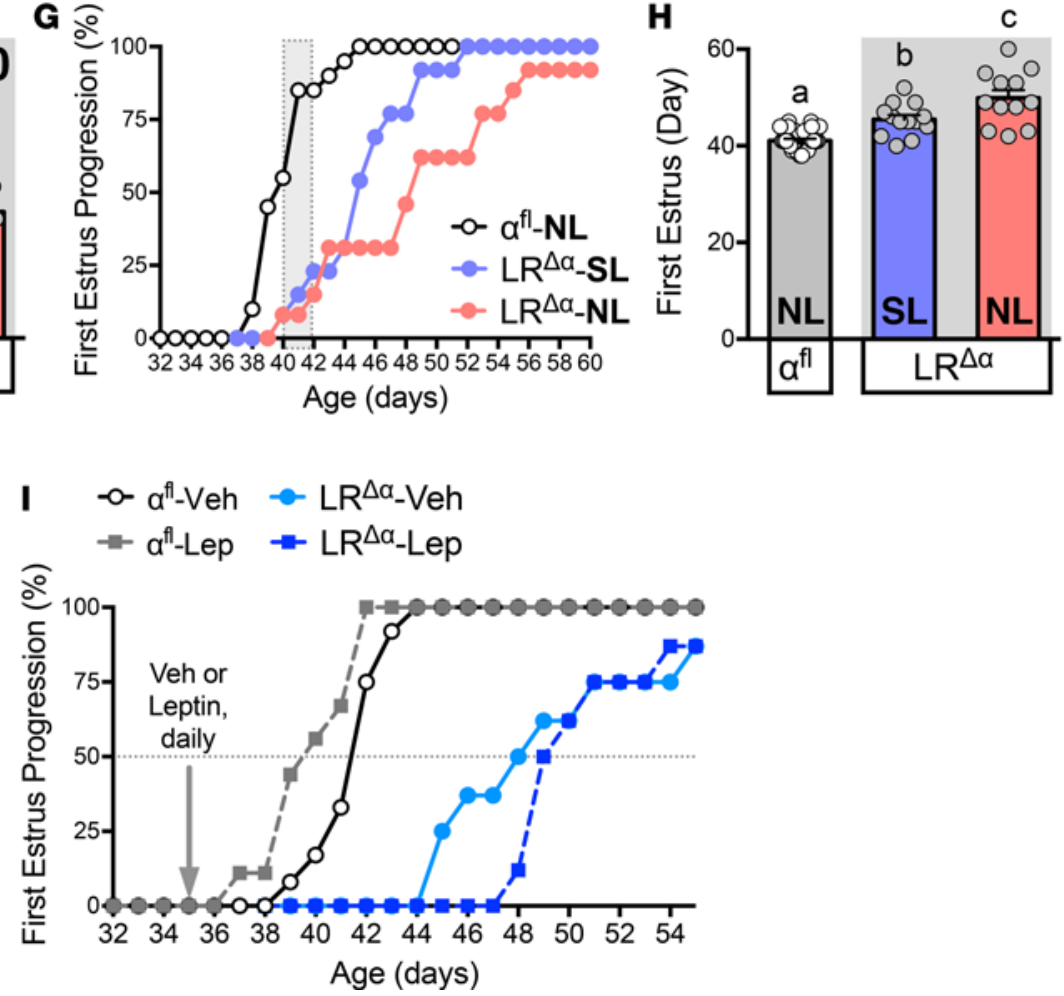

Figure 3. Leptin supplementation does not restore pubertal timing in $\mathbf{L R}^{\Delta \alpha}$ mice. (A) Day of vaginal opening in $\alpha^{f \mid}(n=31)$ and $\mathrm{LR}^{\Delta \alpha}(n=18)$ mice $\left(t_{47}\right.$ $=0.9, P=0.373$ ) and $(B)$ representative graphs of estrous cyclicity and day of first estrus (arrows). (C) Reduced body weight in LR ${ }^{\Delta a}$ mice from normal litter size ( $\left.\mathrm{LR}^{\Delta \alpha}-\mathrm{NL}, n=18\right)$ and small litter size ( $\left.\mathrm{LR}^{\Delta \alpha_{-}} \mathrm{SL}, n=17\right)$ compared with $\alpha^{\mathrm{fl}}-\mathrm{NL}$ females $[n=26 ; F(2,58)=41.05, P<0.0001$ for genotype analysis; $F(18,522)=11.56, P<0.0001$ for interaction] from 2 independent cohorts. (D) Reduced circulating leptin levels at P40 in $L R^{\Delta a}-N L(n=9)$ compared with $\alpha^{\mathrm{fl}}-\mathrm{NL}$ mice $[n=9 ; F(2,21)=3.59, P=0.046]$; levels were similar to those of $\mathrm{LR}^{\Delta \alpha}-\mathrm{SL}(n=6)$. (E) Serum LH levels at P40 [ $\alpha^{\mathrm{fl}}-\mathrm{NL}, n=9$; $\left.\mathrm{LR}^{\Delta \alpha}-\mathrm{SL}, n=10 ; \mathrm{LR}^{\Delta \alpha}-\mathrm{NL}, n=7 ; F(2,23)=2.93, P=0.074\right]$ and $(\mathbf{F})$ ovarian weight in $\alpha^{\mathrm{fl}}-\mathrm{NL}(n=9), \mathrm{LR}^{\Delta a}-\mathrm{SL}(n=10)$, and LR ${ }^{\Delta \alpha}-\mathrm{NL}$ females $[n=9 ; F(2,25)$ $=7.44, P=0.003$ for genotype analysis]. (G) First estrus progression and $(\mathbf{H})$ average age of first estrus detected differences among groups of mice: $\alpha^{f l}-\mathrm{NL}(n=26), \mathrm{LR}^{\Delta a}-\mathrm{SL}(n=13)$, and $\mathrm{LR}^{\Delta a}$-NL females $[n=12 ; F(2,49)=27.81, P<0.0001]$. (I) Effect of daily leptin supplementation on sexual maturation: $\alpha^{f l}$ mice treated with vehicle $(n=12)$ or leptin $(n=9)$, and $\operatorname{LR}^{\Delta \alpha}$ mice treated with vehicle or leptin $(n=8 /$ treatment). Each point represents 1 individual mouse, and all values are presented as mean \pm SEM. ${ }^{*} P<0.05$, ${ }^{*} P<0.01$ versus $L R^{\Delta \alpha}-S L$; $P<0.05$ versus $\alpha^{f 1}-N L$, by repeated-measures 2-way ANOVA with Holm-Sidak's multiple comparisons test in C. Groups with different superscript letters are statistically different by 1-way ANOVA with Newman-Keuls post-hoc analysis in $\mathbf{D}-\mathbf{H}$. 
ing were detected comparing genotypes (Supplemental Figure 5, D-G).

Enhanced leptin sensitivity in adult $L R^{\Delta \alpha}$ mice. PI3K signaling in POMC neurons is required for the acute effects of leptin on food intake $(4,5,20)$. To assess if PI3K $\alpha$ in LR cells is required for the acute anorexigenic effects of leptin, overnight fasted adult $\mathrm{LR}^{\Delta \alpha}$ and $\alpha^{\mathrm{fl}}$ control mice were injected with i.p. leptin or vehicle before lights off and refeeding. Leptin induced a reduction in food intake in control males, which was blunted in $\mathrm{LR}^{\Delta \alpha}$ mice (Figure 6A). Whereas the acute anorexigenic effect was blunted, chronic leptin administration resulted in increased cumulative weight loss over time in $\mathrm{LR}^{\Delta \alpha}$ females (Supplemental Figure $4 \mathrm{~A}$ ). In addition, these mice showed an initial resistance to weight gain when fed with a HFD (Figure 4F).

Acute leptin administration induced a similar increase in suppressor of cytokine signaling 3 (SOCS3) expression in both genotypes (Figure $6 \mathrm{~B}$ ). However, $\mathrm{LR}^{\Delta \alpha}$ mice had enhanced leptin-induced hypothalamic phosphorylated STAT3 (pSTAT3) (Figure 6C). No differences in basal pSTAT3 were detected between genotypes. Additionally, deletion of PI3K $\alpha$ in LR cells resulted in a significant reduction in hypothalamic PTEN protein levels (Figure 6D) and increased fasted basal levels of pAKT at Ser473 residue (Figure 6E). Similarly, $\mathrm{LR}^{\Delta \alpha+\beta}$ females displayed an increase in hypothalamic pAKT and reduced PTEN levels (Supplemental Figure 6, A and B). Together, these data indicate that deletion of PI3K $\alpha$ in LR cells is associated with enhanced hypothalamic leptin sensitivity, likely due to sustained increase of pSTAT3 and pAKT and reduction of PTEN.

Lack of insulin receptor in LR cells is associated with a mild delay of female sexual maturation. The PI3K signaling pathway is also downstream of insulin receptor (InsR) (35). While acute cellular responses to leptin and insulin seem to be segregated in hypothalamic neurons $(19,36)$, the intracellular and/or genomic actions may still overlap. If the colocalization exists, the phenotype of PI3K-deleted mice might be associated with disruption of insulin, not leptin, signaling. However, the degree of InsR/LR coexpression in hypothalamic neurons has not been demonstrated. We initially assessed the coexpression of InsR in LR cells. Intracerebroventricular injections of insulin induced pAKT and FoxO1 translocation in about $60 \%$ of LR neurons of the Arc and about $20 \%$ of LR neurons of the ventral premammillary nucleus (PMV) (Figure 7). These findings indicate that a partial overlap of leptin and insulin signaling in hypothalamic neurons exists.

To assess if a lack of insulin signaling in LR cells recapitulates the phenotype of the PI3K-deleted mice, we generated a mouse line with deletion of InsR in LR-expressing cells (LR ${ }^{\Delta \operatorname{InsR}}$ mice). Gene expression analysis of Arc punches showed a 50\% reduction of Insr and no Lepr changes in $\mathrm{LR}^{\Delta \mathrm{InsR}}$ mice (Figure $8 \mathrm{~A})$. The $\mathrm{LR}^{\Delta \mathrm{InsR}}$ male mice had body weight similar to controls. No changes in body length, food intake, or energy expenditure were detected. A decrease in fasting glucose levels was apparent, but no change in glucose tolerance was observed (Figure 8, B-H). The LR ${ }^{\Delta I n s R}$ female mice displayed similar body weight, body length, and timing of puberty onset as well as a mild delay for first estrus (puberty completion). No differences in estrous cycle length and fertility were observed comparing $L^{\Delta \mathrm{InsR}}$ and $\mathrm{InsR}^{\mathrm{fl}}$ control mice (Figure 8, I-L). These findings indicate that the metabolic, growth, and reproductive phenotypes of the PI3K-deleted mice are not due to the lack of insulin signaling in LR cells.

\section{Discussion}

Studies from several groups have suggested that PI3K acts as a common intracellular signaling in leptin and insulin function $(4,6,8,37)$. To dissociate the effects of both hormones and gain insights into the role of PI3K downstream of leptin action, we deleted PI3K catalytic subunits only in LR cells. A similar approach has produced compelling data on the requirement of STAT3, STAT5, and PTEN actions downstream of leptin signaling $(14,23,26)$. Because the coexpression of LR and InsR has not been systematically investigated, we assessed if lack of insulin signaling in LR cells accounts for the phenotype observed following LR PI3K deletion. $\mathrm{LR}^{\Delta \mathrm{InsR}}$ mice are overtly normal, with only a mild delay for pubertal completion in females. This phenotype is similar to what we observed in mice with deletion of InsR in kisspeptin neurons (38) and demonstrates that the global phenotypic changes caused by PI3K deletion in LR cells are not due to blockade of insulin signaling.

The metabolic phenotype of $\mathrm{LR}^{\Delta \alpha+\beta}$ and $\mathrm{LR}^{\Delta \alpha}$ mice may seem unexpected considering previous data obtained with inactivation of PI3K signaling in POMC and SF1 neurons. It is important to emphasize that although the melanocortin cells in the Arc and SF1 neurons in the VMH have been the main focus of research in PI3K action in metabolic regulation (16-18, 20, 21), those populations are heterogeneous; only subsets of POMC, AgRP, and SF1 neurons coexpress LR $(19,36,39)$. Subpopulations of those neurons are also responsive to insulin and other growth factors $(18,19,36)$. Therefore, it is not clear if the metabolic phenotype of those mice is associated with lack of leptin, insulin, or other signals. 


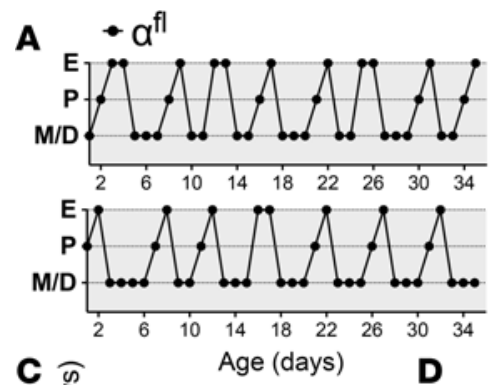

c

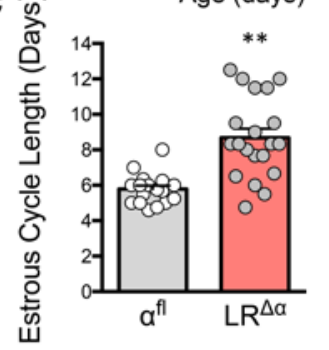

D
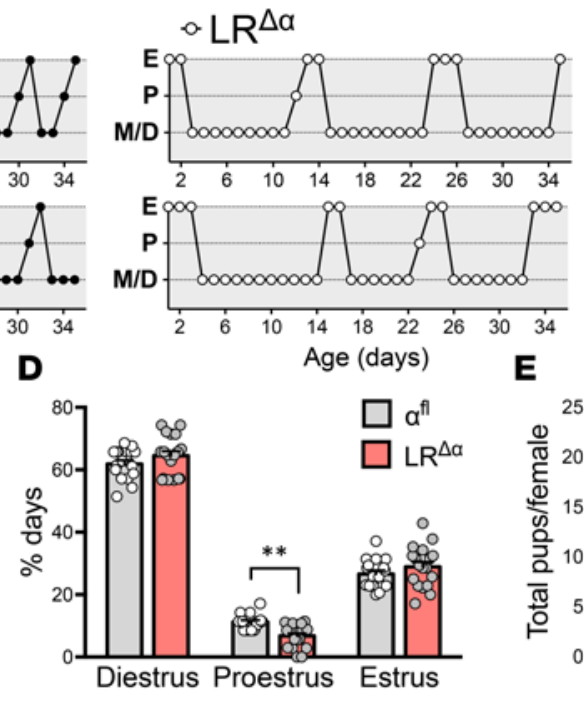

E
B

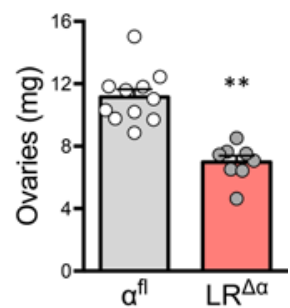

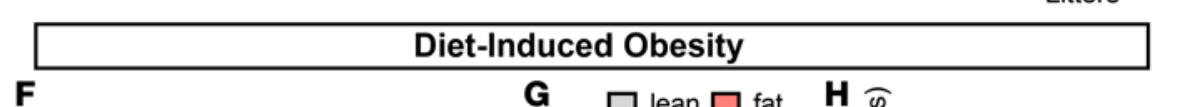

$\mathbf{F}$
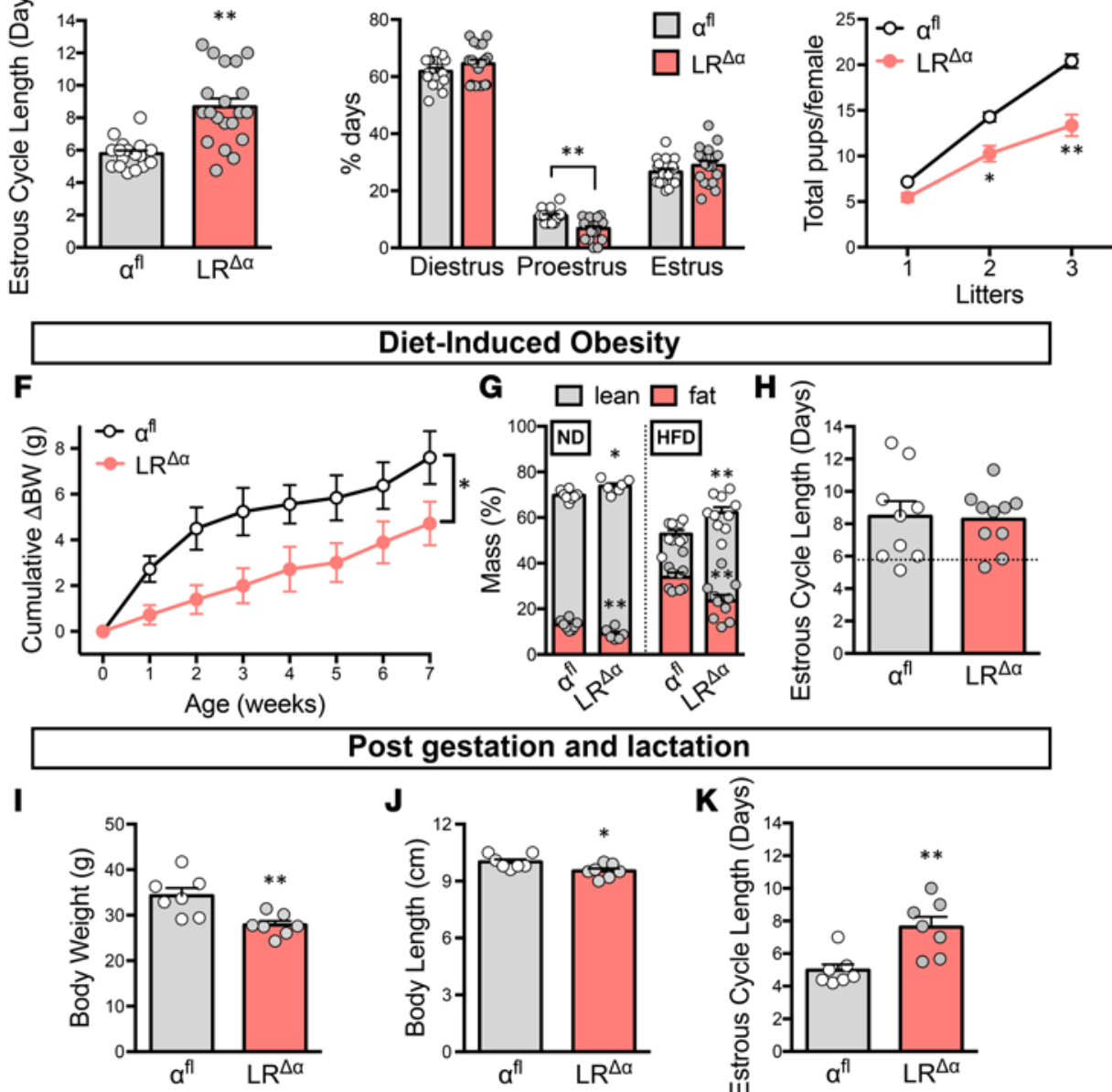

Post gestation and lactation
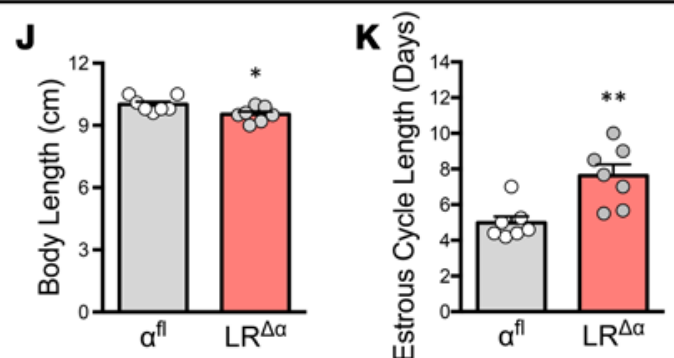

Figure 4. $\mathrm{LR}^{\Delta a}$ females show reproductive deficits. (A) Representative diagrams for estrous cycles in $\alpha^{\mathrm{fl}}$ and $\mathrm{LR}^{\Delta a}$ mice. (B) Reduced ovarian weight of $L R^{\Delta a}(n=8)$ compared with $\alpha^{f l}$ mice $\left(n=11 ; t_{17}=5.99, P<0.0001\right)$. (C) Longer estrous cycle duration in LR $\operatorname{LR}^{\Delta a}$ mice $(n=19)$ with respect to $\alpha^{f l}$ mice $\left(n=18 ; t_{36}=5.09, P<0.0001\right)$.

(D) Percentage of days in metestrus, diestrus, proestrus, or estrus phases $\left(t_{33}=4.21, P=0.0001\right.$ versus controls in proestrus). (E) The ratio of total pups per dam is diminished in $\mathrm{LR}^{\Delta \alpha}$ mice compared with $\alpha^{f 1}$ mice $[F(1,34)=20.08, P<0.0001]$. (F) Reduced cumulative body weight gain $(\Delta B W)$ in LR $R^{\Delta \alpha}(n=10)$ compared with $\alpha^{f \mid}(n$ $=9)$ animals on high-fat diet [HFD; $F(1,19)=5.61, P=0.029$ ]. (C) Differences in lean and fat mass in LR ${ }^{\Delta a}$ mice on HFD $\left(t_{17}=3.1, P=0.007\right.$ for lean mass; $t_{17}=3.05, P=$ 0.007 for fat mass) or normal chow diet (ND; $\alpha^{f l}, n=8 ; \mathrm{LR}^{\Delta \alpha}, \mathrm{n}=6 ; t_{12}=2.95, P=0.012$ for lean mass; $t_{12}=3.19, P=0.008$ for fat mass). (H) Estrous cycle length after 14 weeks on HFD ( $\left.t_{17}=0.168, P=0.87\right)$. Dotted line represents estrous cycle duration of control $\alpha^{f l}$ females on ND. (I) Reduced body weight $\left(t_{12}=3.38, P=0.005\right)$, and (J) body length in LR ${ }^{\Delta a}$ compared with $\alpha^{f l}$ dams ( $n=7 /$ group) after gestation and lactation $\left(t_{12}=2.53, P=0.026\right)$. (K) Longer estrous cycle length in $\mathrm{LR}^{\Delta a}$ dams after gestation and lactation ( $n=7$ /group; $t_{12}=3.6, P=0.004$ ). Each point represents 1 individual mouse. Data are presented as mean $\pm S E M$. ${ }^{*} P<0.05$, ${ }^{* *} P<0.01$, by 2-way repeated-measures ANOVA with Holm-Sidak's post-hoc test in $\mathbf{E}$ and $\mathbf{F}$ and by 2-tailed Student's $t$ test in B-D and G-K.

Here, we used the selective deletion of PI3K catalytic subunits in LR cells. This approach has produced important data on the role of JAK/STAT, IRS2, and PTEN signaling downstream of leptin action (14, 25, 26). We were able to dissociate the effects of PI3K $\alpha$ and PI3K $\beta$ in metabolic regulation and demonstrate the requirement for PI3K $\alpha$ in LR for growth and reproduction. Disruption of thermogenesis and locomotor activity and altered glucose homeostasis were only observed following deletion of PI3K $\beta$ in LR cells. Our findings indicate a dissociated role of distinct PI3K catalytic subunits downstream of leptin signaling, which has also been suggested by studies using chemically defined hypothalamic neurons $(14,20,21)$. 

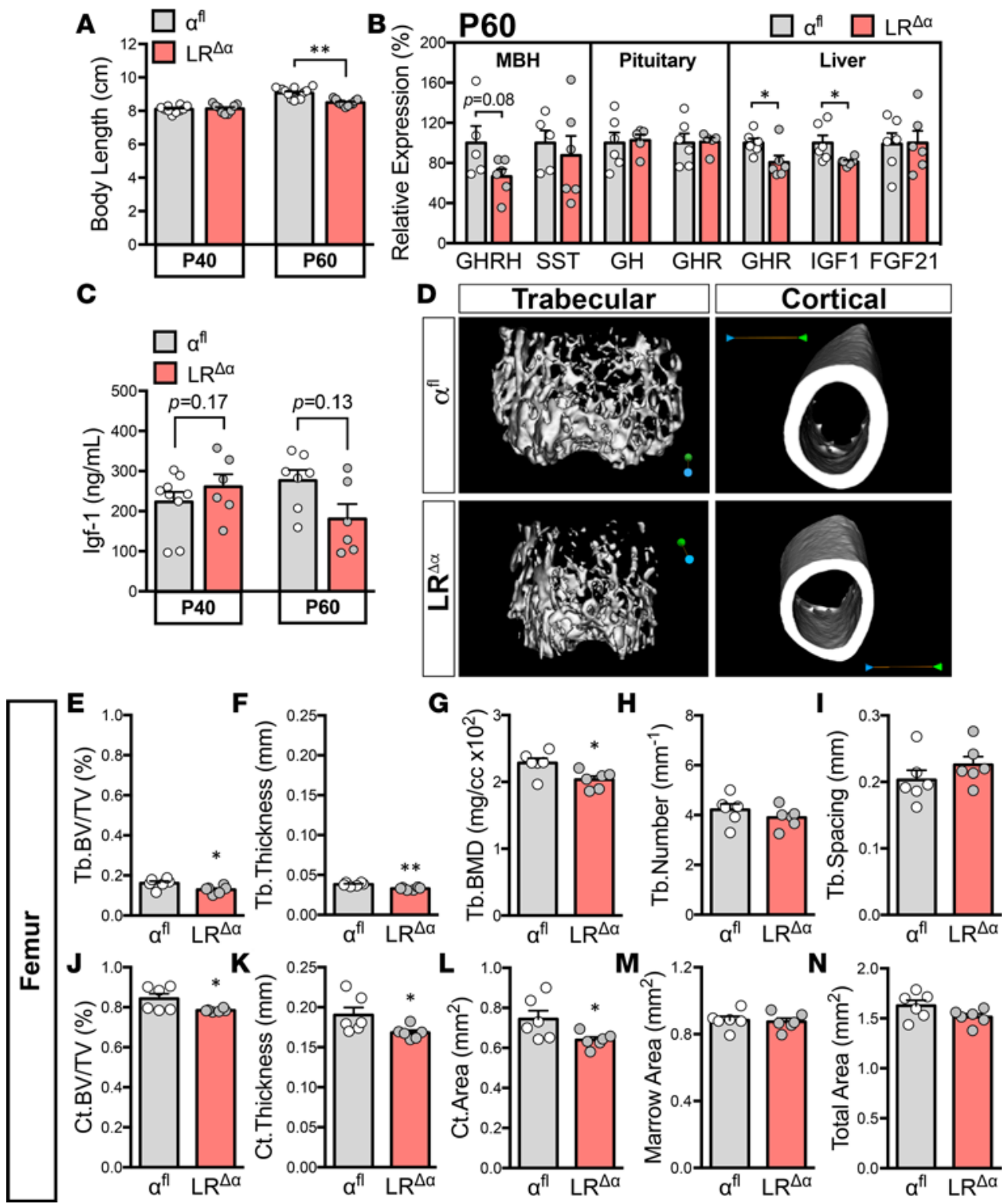

$\mathbf{N}$

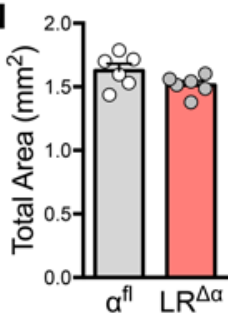

Figure 5. LR ${ }^{\Delta a}$ females show decreased bone volume and bone mineral density. (A) Normal body length at P40 in LR ${ }^{\Delta a}$ ( $\left.n=11\right)$ mice with respect to $\alpha^{f l}$ mice $\left(n=12 ; t_{17}=0.31, P=0.76\right)$, with reduced body length relative to $\alpha^{f l}$ mice at $\mathrm{P} 60\left(\alpha^{f 1}, n=15 ; \mathrm{LR} \Delta \alpha, n=14 ; t_{21}=5.2, P<0.0001\right)$. (B) Relative mRNA expression of growth hormone-releasing hormone (GHRH; $\left.t_{9}=1.94, P=0.085\right)$ and somatostatin $(\mathrm{SST})$ in the mediobasal hypothalamus (MBH) and growth hormone $(\mathrm{CH})$ and $\mathrm{GH}$ receptor (GHR) in pituitary. GHR $\left(t_{10}=2.38, P=0.039\right)$, insulin-like growth factor 1 (ICF1; $n=5-6 / \mathrm{group} ; t_{10}=2.47, P=$ 0.033 ) and fibroblast growth factor 21 (FGF21) liver. (C) Similar circulating Igf-1 levels at P40 ( $\left.\alpha^{f 1}, n=9 ; R^{\Delta \alpha}, n=6 ; t_{14}=1.46, P=0.17\right)$ and P60 ( $n=6-7$ ) group; $t_{10}=1.67, P=0.13$ ). (D) Representative images of trabecular (Tb) and cortical (Ct) femora. (E) Reduced percentage of bone volume/total volume (Tb.BV/TV; $\left.t_{10}=2.53, P=0.03\right),(\mathbf{F})$ thickness $\left(t_{10}=4.76, P=0.0008\right)$, and $(\mathbf{C})$ bone mineral density (Tb.BMD; $\left.t_{10}=2.78, P=0.02\right)$ in LR ${ }^{\Delta \alpha}$ mice versus control females. (H) Similar trabecular number (Tb.Number; $\left.t_{10}=0.31, P=0.3\right)$ and (I) spacing between genotypes $\left(t_{10}=1.19, P=0.26\right)$. Reduced cortical (J) BV/TV $\left(t_{10}=2.39, P=0.038\right)$, $(K)$ thickness $\left(t_{10}=2.23, P=0.05\right)$, and $(\mathrm{L})$ area in $\mathrm{LR}^{\Delta \alpha}$ females $\left(t_{10}=2.31, P=0.043\right)$. No differences in $(\mathrm{M})$ marrow area $\left(t_{10}=0.3, P=0.77\right)$ or $(\mathbf{N})$ total area $\left(t_{10}=1.84, P=0.1, n=6 /\right.$ group $)$. Each point represents 1 individual mouse. Data are presented as mean $\pm \mathrm{SEM}$. ${ }^{*} P \leq$ $0.05,{ }^{* *} P<0.01$; by 2-tailed Student's $t$ test.

The metabolic similarities between mice with deletion of PI3K and those with deletion of PTEN in LR cells were intriguing $(14,20,21)$. PTEN is a phosphatase associated with conversion of PIP3 to PIP2, resulting in PI3K inactivation (40). We report that lack of PI3K subunits induced a decrease of PTEN expression that can also affect other signaling pathways, including the MAPK pathway. This effect may have mimicked the phenotype of partial deletion of PTEN in LR cells (14). Moreover, increased basal levels of pAKT and leptin-induced pSTAT3 produced a phenotype of increased leptin sensitivity in metabolic regulation. Our findings are also in agreement with previous studies showing that PI $3 \mathrm{~K} \alpha$ is required for the 
A

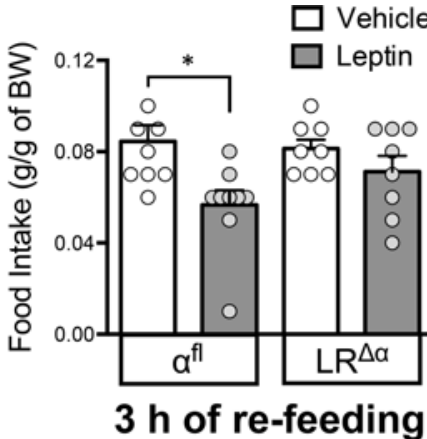

B

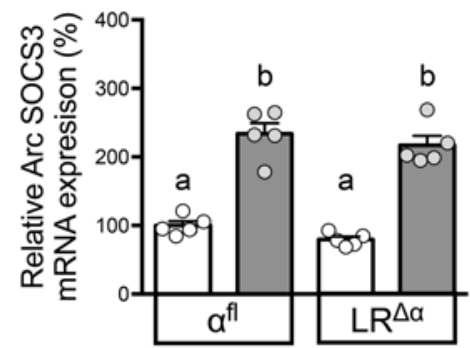

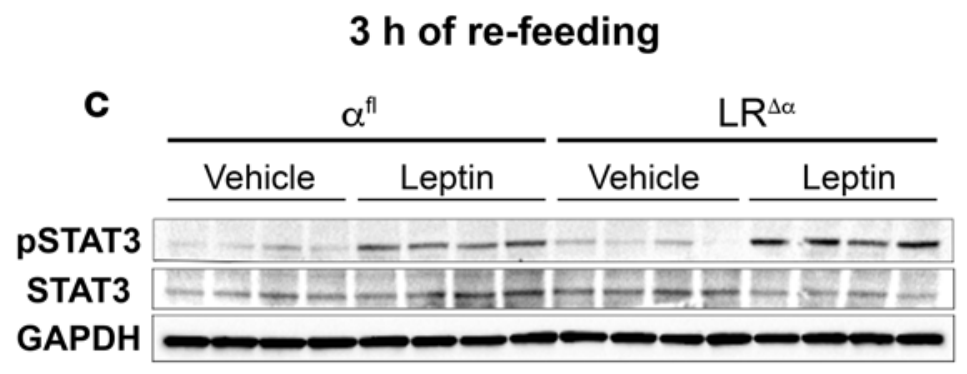
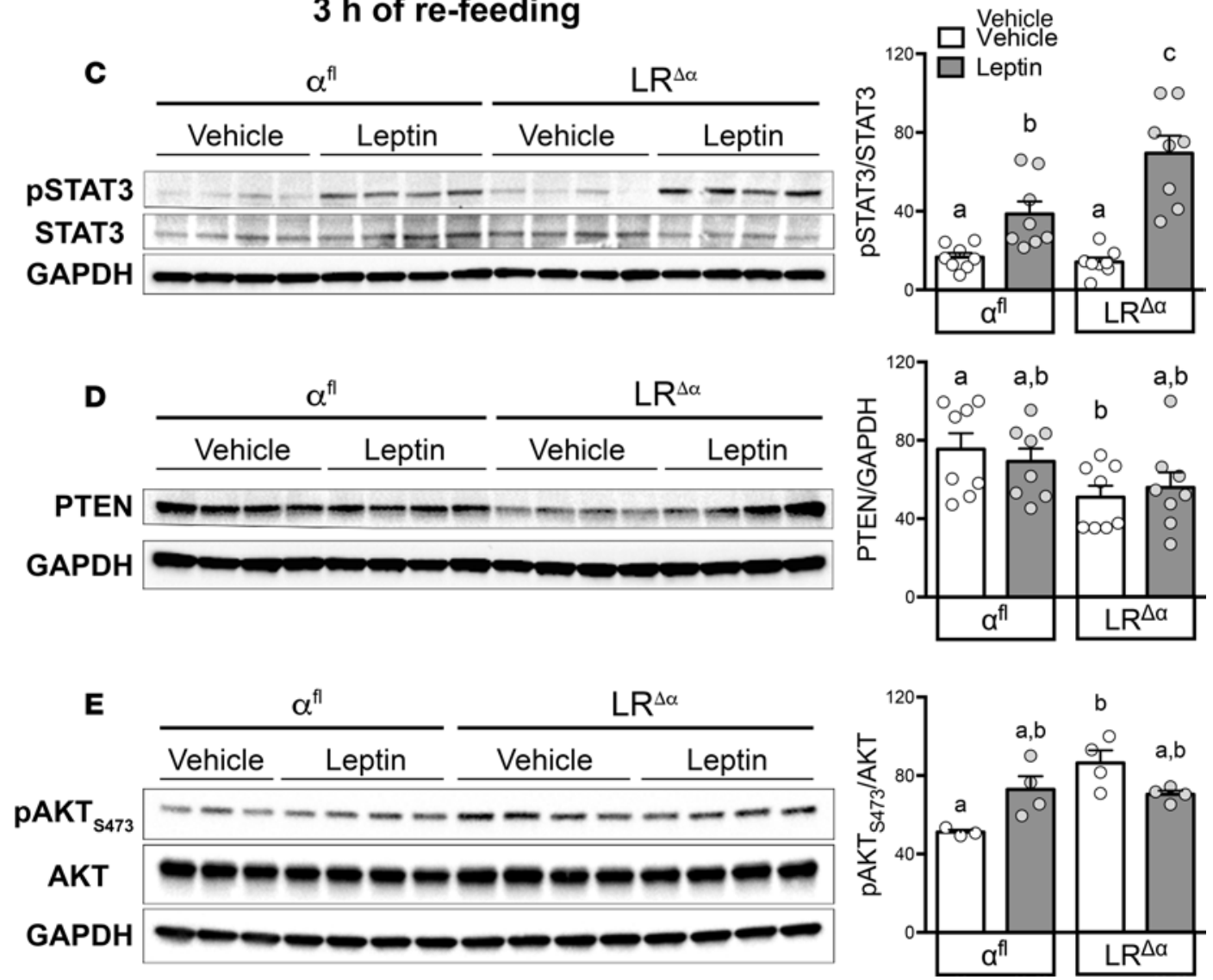

Figure 6. LR ${ }^{\Delta a}$ mice show enhanced leptin sensitivity and reduced hypothalamic PTEN expression. (A) Blunted acute anorexigenic effect of leptin ( 3 hours of refeeding) in $\operatorname{LR}^{\Delta a}\left(n=8 /\right.$ treatment) compared with $\alpha^{f 1}(n=9 /$ treatment) males $[F(1,30)=8.89, P=0.006]$. (B) Leptin induced similar SOCS3 mRNA expression in the arcuate nucleus (Arc) of fasted $\mathrm{LR}^{\Delta \alpha}$ and $\alpha^{f 1}$ females $[n=5 /$ group; $F(1,16)=150.7, P<0.0001]$. (C) Representative Western blotting and relative protein quantification from hypothalamic extracts show enhanced leptin-induced pSTAT3 in fasted LR ${ }^{\Delta \alpha}$ compared with $\alpha^{f 1}(n=8 /$ treatment, females $[F(1,28)=6.3, P=0.018$ for genotype analysis; $F(1,28)=46.35, P<0.0001$ for treatment analysis]. (D) Reduced PTEN expression from hypothalamic extracts of fasted mice injected with vehicle or leptin $[F(1,28)=7.02, P=0.013 ; n=8$ /treatment, females]. (E) Representative Western blotting and relative protein quantification of pAKT at Ser473 residue ( pAKT $\left._{543}\right)$ from hypothalamus of fasted mice injected with vehicle or leptin $(n=3-4 /$ treatment, females) showed increased $\mathrm{PAKT}_{5473}$ expression in $\mathrm{LR}^{\Delta \alpha}$ females $[F(1,11)=10.1, P=0.009]$. Each point represents 1 individual mouse. Data are presented as mean $\pm \mathrm{SEM}$. ${ }^{*} P<$ 0.05 versus control mice; groups with different superscript letters are statistically different by 2-way ANOVA with Tukey's post-hoc analysis.

acute effects of leptin on food intake and, together, indicate that POMC neurons expressing LR relay this acute response (4). The disruption of AgRP regulation (mRNA and protein levels) also suggests that PI3K in AgRP neurons is necessary for energy balance during metabolic challenges $(7,16)$.

PI3K subunits in chemically identified hypothalamic neurons are required for insulin and glucose homeostasis $(6,13,14,22)$. Except for the low levels of insulin in $\mathrm{LR}^{\triangle \alpha+\beta}$ mice (also observed in mice with deletion of PTEN in LR cells), our findings indicate that these responses are driven by cells outside the LR population $(13,35)$. Previous studies have shown that deletion of insulin receptor substrate 2 (IRS2) in LR cells, thought to be upstream of leptin action in PI3K, results in obesity, glucose intolerance, and insulin 
A
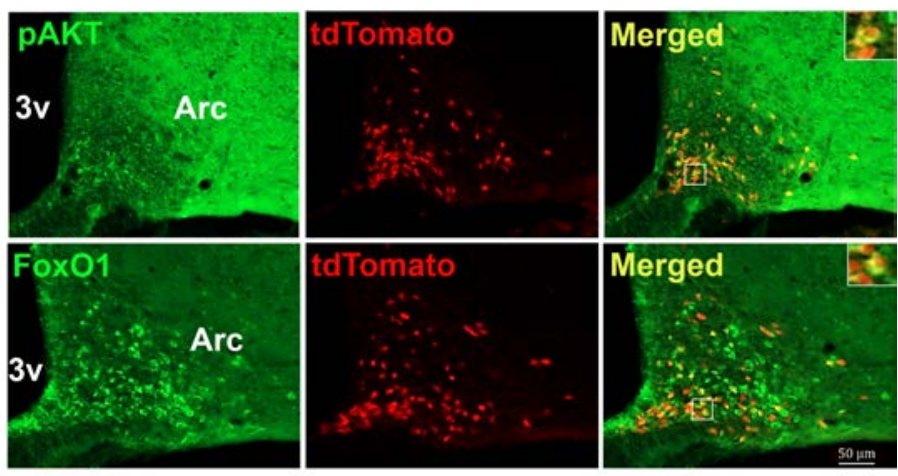

B

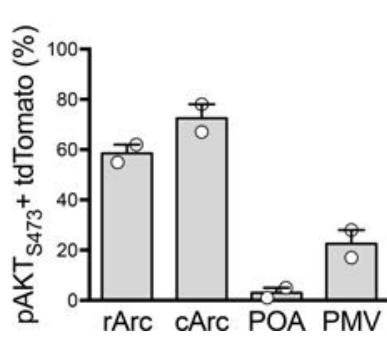

C

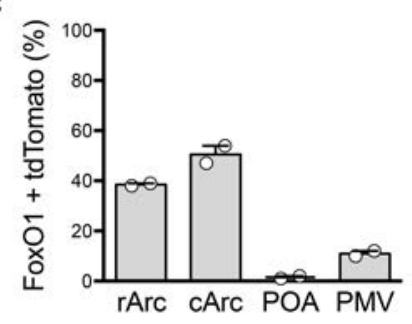

Figure 7. Insulin-induced pAKT and Fox01 translocation in hypothalamic LR cells. (A) Representative images of the hypothalamic arcuate (Arc) nucleus and quantification of insulin-induced (B) pAKT at $\mathrm{S} 473$ residue $\left(\mathrm{pAKT}_{5473}\right.$ ) and (C) Fox01 immunoreactivity in LR neurons coexpressing tdTomato in several hypothalamic nuclei. Brains were collected after 15 minutes of intracerebroventricular insulin administration to fasted animals ( $n=2$ /group). rArc, rostral arcuate nucleus; cArc, caudal Arc; POA, preoptic area; PMV, ventral premammillary nucleus; 3v, third ventricle. Each point represents 1 individual mouse. Data are presented as mean \pm SEM. Scale bar: $50 \mu \mathrm{m}$.

resistance (41). Those mice were still responsive to leptin, suggesting developmental adaptations, redundancy, or unknown mechanisms may have been triggered by this manipulation. It also suggests that blockade of either IRS2 or PI3K catalytic subunits alters distinct intracellular signaling responses in LR cells.

$\mathrm{LR}^{\Delta \alpha+\beta}$ and $\mathrm{LR}^{\Delta \alpha}$ mice showed apparent similarities to those with heterozygous kinase-dead PI3K $\alpha$ mutation (D993A). The D993A mice have reduced body weight and body length (1), but, in contrast to $\mathrm{LR}^{\Delta \alpha+\beta}$ and $\mathrm{LR}^{\Delta \alpha}$ mice, the growth phenotype of the D993A mice is detected during early postnatal development, suggesting a disruption of IGF1 signaling (1). Because the decreased growth of $\mathrm{LR}^{\Delta \alpha+\beta}$ and $\mathrm{LR}^{\Delta \alpha}$ mice is only detected following pubertal maturation, IGF1 signaling is not the major player. Rather, our findings indicate that leptin action in growth and bone accrual is mediated by PI3K signaling $(42,43)$. This is in line with the reduced body length of leptin signaling deficient mice and the lack of a growth phenotype following inactivation of STAT signaling in LR cells $(23,24)$.

The consequences of these genetic ablations to the reproductive physiology are striking. The $\mathrm{LR}^{\Delta \alpha}$ mice have a phenotype reminiscent of states of negative energy balance, i.e., delayed sexual maturation, prolonged oligoovulatory cycles, and subfertility $(44,45)$. Due to the metabolic phenotype of the $\mathrm{LR}^{\Delta \alpha}$ mice, we further assessed if the reproductive deficits were secondary to their persistent condition of negative energy balance. This hypothesis was refuted by data from two distinct nutritional and pharmacological paradigms. While restoration of leptin levels in wild-type mice under negative energy balance improved the reproductive parameters (46), $\mathrm{LR}^{\Delta \alpha}$ females were unresponsive to leptin's effect.

The identity of LR cells driving the reproductive phenotype of $\mathrm{LR}^{\Delta \alpha}$ mice is unknown. LR is also expressed in gonads (47), but most of leptin's effects on the reproductive axis are relayed by the brain (4850). One potential candidate is the AgRP neuronal population, due to its role in leptin's function and the disrupted expression of AgRP mRNA and peptide of $L^{\Delta \alpha}$ mice (51-53). Leptin acts to downregulate AgRP expression and to inhibit AgRP cell activity (54-56). These actions of leptin require PI3K signaling $(7,8)$. Deletion of PI3K signaling in LR cells caused lack of responsiveness of AgRP to metabolic cues, potentially leptin, resulting in higher AgRP expression in fed conditions, associated with increased food intake. The AgRP neurons have inhibitory actions on the reproductive axis (51-53). Therefore, high levels of AgRP may have disrupted the reproductive function of $\mathrm{LR}^{\Delta \alpha}$ mice. Alternatively, PI3K is also required for the acute neuronal response of LR cells in the PMV, a key neuronal nucleus for pubertal development in females $(17,50)$. Lack of PI3K signaling in PMV LR neurons precludes the cellular responses to leptin potentially disrupting pubertal maturation and the reproductive function.

The regulation of PI3K signaling is complex, and the genetic manipulation of specific subunits may generate unexpected phenotypes. Examples of this are mouse models with deletion of p $85 \alpha$ or $p 85 \beta$ regulatory subunits. Although PI3K is crucial for insulin action in glucose homeostasis, the genetic dis- 

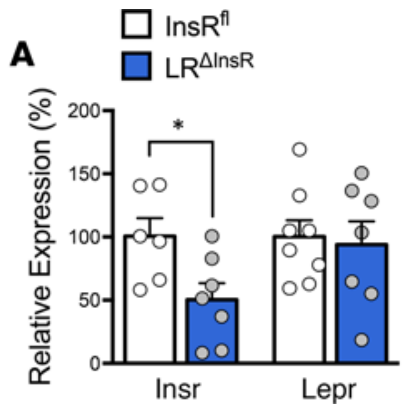

B
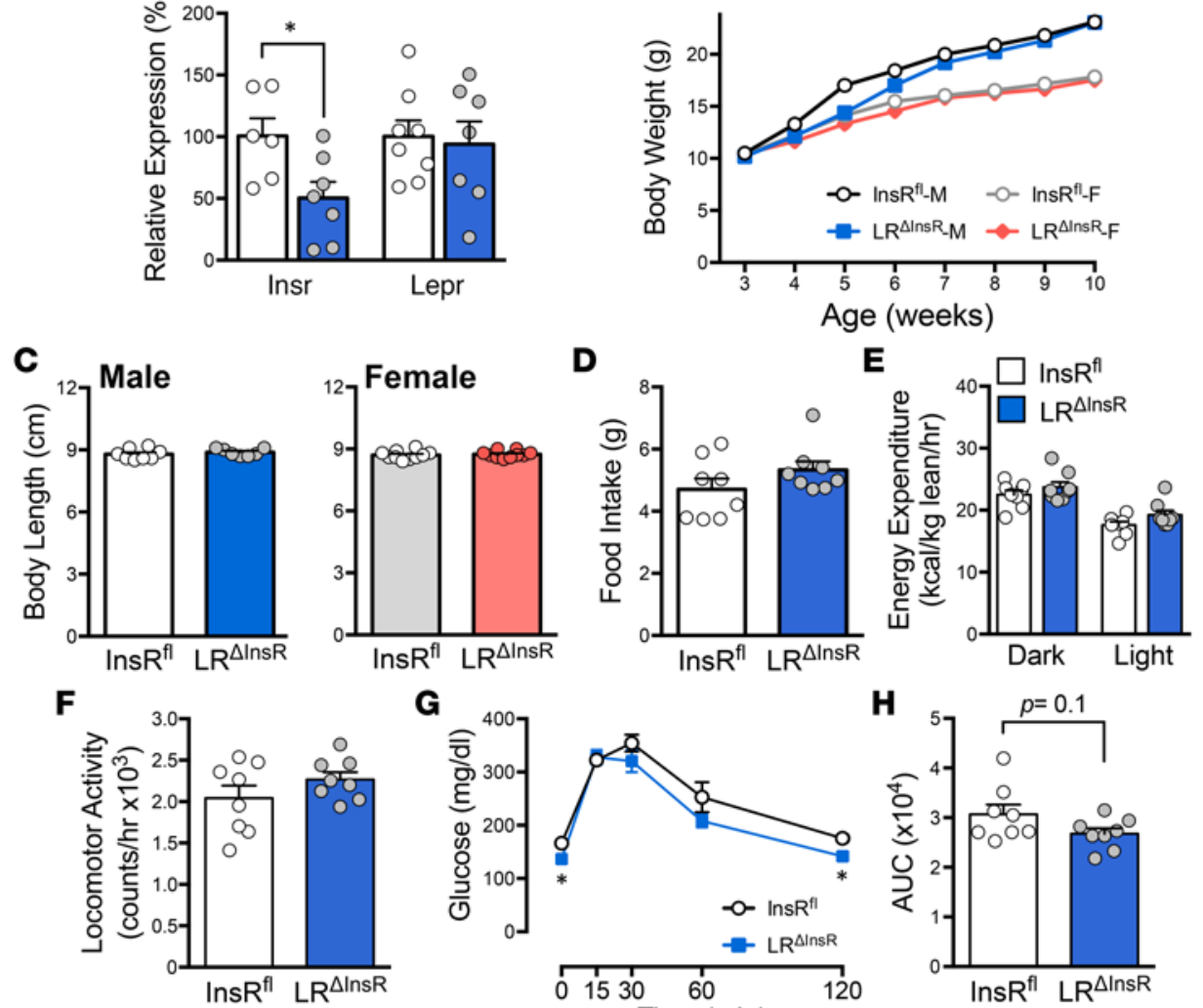

G
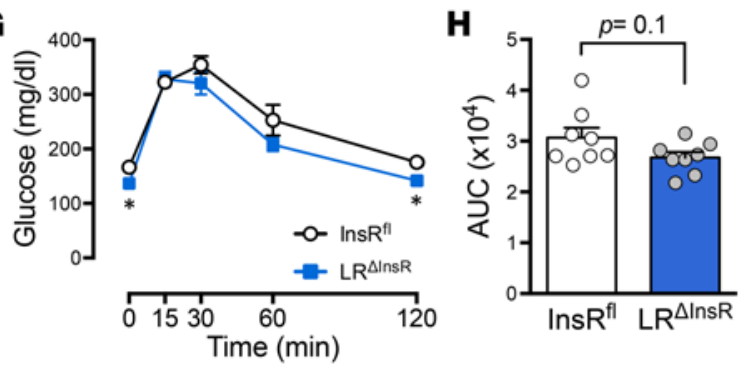
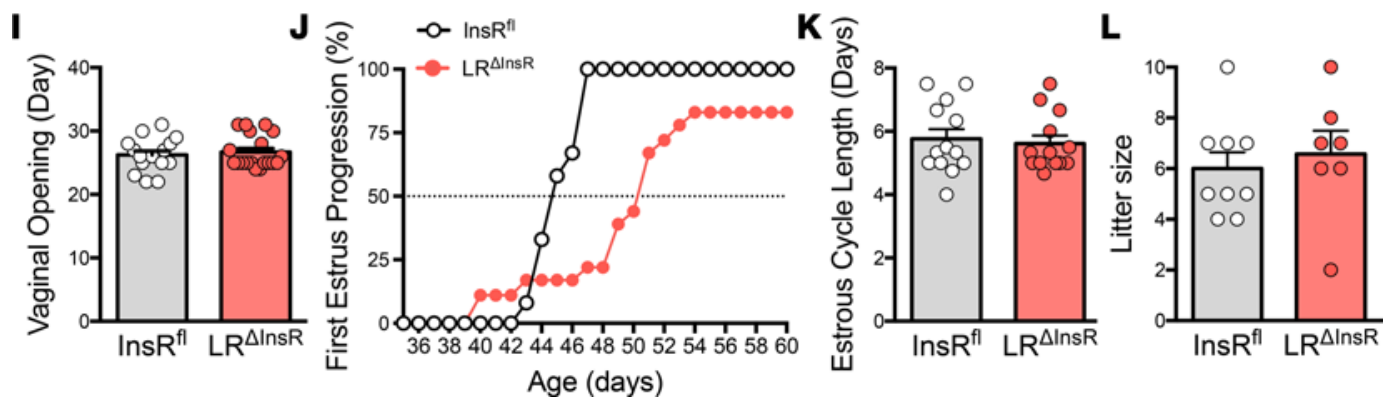

Figure 8. Assessment of metabolic and reproductive phenotype of mice with deletion of InsR in LR cells. (A) Reduced relative Insr mRNA expression in mice with deletion of InsR in LR cells (LR $\left.{ }^{\Delta \operatorname{lnsR}}\right)\left(t_{11}=2.57, P=0.026\right)$ and similar Lepr (b, long isoform) gene expression in Arc punches of adult $L^{\Delta / n s R}$

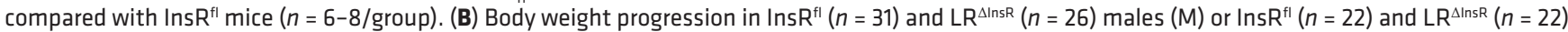
females (F) from 3 independent cohorts. (C) Snout-anus distances of $\operatorname{InsR}^{f 1}(n=8)$ and $\operatorname{LR}^{\Delta \ln s R}(n=7)$ males and InsR $R^{f l}$ and $L^{\Delta \operatorname{lnsR}}(n=10 / g r o u p)$ females at 12 weeks of age were not different. (D-F) CLAMS study in males ( $n=8 /$ group) for total food intake (24 hours; $\mathbf{D}$ ); (E) energy expenditure averages for dark and light phases; and (F) locomotor activity, which were not different between genotypes. (C) Clucose levels at basal (0 minutes), 15, 30,60 , and 120 minutes after oral glucose tolerance test (OGTT; $t_{14}=2.73, P=0.016$ at basal; $t_{14}=2.72, P=0.016$ at 120 minutes). (H) Quantification using area under the curve

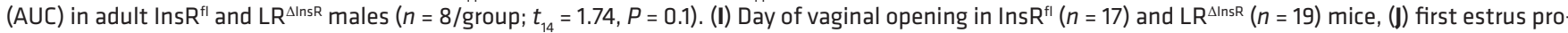

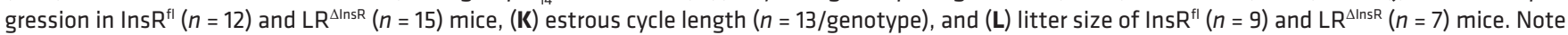
a delay in pubertal completion in $\mathrm{LR}^{\Delta \mathrm{nnsR}}$ mice (J). Each point represents 1 individual mouse. Data are presented as mean $\pm \mathrm{SEM}$. ${ }^{*} P<0.05$ versus control by repeated-measures 2-way ANOVA with Holm-Sidak's multiple comparisons test in B and 2-tailed Student's $t$ test in $\mathbf{A}$ and $\mathbf{C}-\mathbf{L}$.

ruption of p85 subunits increases insulin sensitivity and causes hypoglycemia (57-60). Our findings in $\mathrm{LR}^{\Delta \alpha}$ mice indicate a similar effect with increased leptin sensitivity for metabolic regulation suggested by the decrease in body weight and increase in leptin-induced pSTAT3 in the hypothalamus. Although the metabolic effects of leptin in our experimental model appear potentiated, an impairment of growth and reproductive physiology is apparent. These results indicate that leptin's effects on metabolism, on growth, and on reproduction engage distinct molecular pathways. 
Comprehensive genomic analyses in humans have identified PI3K as one of the pathways associated with age at menarche (61). Our findings strengthen these findings and show that PI3K signaling in LR cells is a crucial component of pubertal maturation and reproductive function in adult life. The higher leptin sensitivity in metabolic control and the decreased growth of $\mathrm{LR}^{\Delta \alpha}$ mice also make PI3K a potential player in conditions of delay in growth and puberty in humans and in hypothalamic amenorrhea of women in negative energy balance. Our findings also emphasize the need for a systematic evaluation of PI3K action in whole-body physiology, as clinical trials are on the way to assess the effects of using $\mathrm{PI} 3 \mathrm{~K} \alpha$ inhibitors as a potential therapeutic target in oncology (62).

\section{Methods}

Animal models. LepR-Cre (JAX mice, stock 008320) (63), Pik3ca (stock 017704) (64), Pik3cb (stock 017705) (2), Insr (stock 006955) (65), and reporter R26-tdTomato (stock 007914) $(27,66)$ mice were housed in an Association for Assessment and Accreditation of Laboratory Animal Care-accredited animal facility at the University of Michigan under controlled light cycle (12 hours on/off) and temperature $\left(21^{\circ} \mathrm{C}-23^{\circ} \mathrm{C}\right)$ conditions. Inbred mouse strains were maintained in the original mixed genetic background C57BL/6 Sv129, and mice with excised genes were bred to homozygosity and were housed by genotype to avoid pheromone synchronization (67). Mice were fed with a phytoestrogen-reduced diet 2016 (16\% protein $/ 4 \%$ fat), a higher protein and fat phytoestrogen-reduced diet 2019 (19\% protein/8\% fat) when breeding, or a HFD (42\% fat, TD.88137, Envigo) with free access to water. A phytoestrogen-reduced diet was used to avoid the effect of exogenous estrogen in reproductive physiology.

To inactivate the catalytic PI3K p110 $\alpha$ and $\mathrm{p} 110 \beta$ subunits or InsR in LR-expressing neurons,

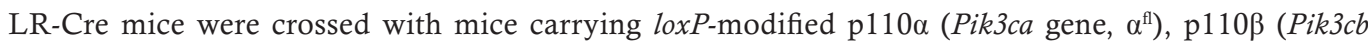
gene, $\left.\beta^{\mathrm{fl}}\right)$, or InsR ${ }^{\mathrm{fl}}$ alleles. Preliminary observations indicated that enhanced Cre-mediated excision was obtained in LR-Cre homozygous animals (Supplemental Figure 2, A and B, and ref. 68). Therefore, our experimental mice were those homozygous for the Lepr-Cre allele (LR $\left.{ }^{\text {cre }}{ }^{\text {cre }}\right)$ and homozygous

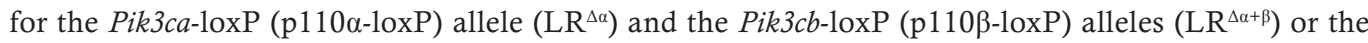
Insr-loxP allele $\left(\mathrm{LR}^{\Delta \mathrm{Ins}}\right)$. Control groups were comprised of mice homozygous for the floxed alleles $\left(\alpha^{\mathrm{fl}}, \alpha^{\mathrm{fl}}+\beta^{\mathrm{fl}}\right.$, and $\left.\mathrm{Ins} \mathrm{R}^{\mathrm{fl}}\right)$ and for the Cre allele $\left(\mathrm{LR}^{\text {cre/cre }}\right)$. In order to visualize the LR-expressing neurons, we crossed $\mathrm{LR}^{\text {cre/cre }}, \mathrm{LR}^{\Delta \alpha}, \mathrm{LR}^{\Delta \alpha+\beta}$, or $\mathrm{LR}^{\Delta \mathrm{InsR}}$ mice with the $\mathrm{R} 26$-tdTomato reporter mouse $(27,69)$. Mice were genotyped at weaning ( 3 weeks of age) and at the end of the experiments using the pairs of primers described in Supplemental Table 1. PCR amplification of the genomic regions flanked by loxP sites, combined with the detection of the Cre transgene in tail-derived DNA, was performed (REDExtract-N-Amp Tissue PCR Kit XNAT, MilliporeSigma).

Assessment of metabolic phenotyping. Body weight of mutant and control mice was monitored weekly throughout the experiments. Oxygen consumption $\left(\mathrm{VO}_{2}\right)$, carbon dioxide production $\left(\mathrm{VCO}_{2}\right)$, spontaneous motor activity, and food intake were measured using the Comprehensive Laboratory Monitoring System (CLAMS, Columbus Instruments), an integrated open-circuit calorimeter equipped with an optical beam activity monitoring device, at the University of Michigan Animal Phenotyping Core. Adult $\mathrm{LR}^{\Delta \alpha+\beta}, \mathrm{LR}^{\Delta \alpha}$, and control ( $n=8$ /genotype) males were weighed before the measurements and individually placed into the sealed chambers ( 7.9 inches $\times 4$ inches $\times 5$ inches) with free access to food and water. The study was carried out in an experimentation room set at $21^{\circ} \mathrm{C}-23^{\circ} \mathrm{C}$ with 12 -hour-light/dark cycles. The metabolic assessments were carried out continuously for 96 hours after 48 hours of adaptation. During this time, animals were provided with food and water through the equipped feeding and drinking devices located inside the chamber. Food intake for each animal was monitored through a precision balance attached below the chamber. $\mathrm{VO}_{2}$ and $\mathrm{VCO}_{2}$ in each chamber were sampled sequentially for 5 seconds in a 10-minute interval, and the motor activity was recorded every second in $x$ and $z$ dimensions. The airflow rate through the chambers was adjusted to the level to keep the oxygen differential around $0.3 \%$ at resting conditions. Body fat and lean mass were measured using an NMR-based analyzer (Minispec LF90II, Bruker Optics) in conscious mice. RER was calculated as $\mathrm{VCO}_{2} / \mathrm{VO}_{2}$, and total energy expenditure was obtained based on the following formula: $\mathrm{EE}=\left[\mathrm{VO}_{2} \times(3.815+1.232 \times \mathrm{RER})\right]$.

Assessment of reproductive phenotype. Timing of puberty onset was monitored daily after weaning for external signs of puberty onset by determining the day of vaginal opening or balanopreputial separation and timing for the occurrence of first estrus, defined by the identification of keratinized cells for 2 consecutive days after 2 previous days with leukocytes in the vaginal lavage or by an estrus stage preceded by a proestrus stage $(38,70,71)$. 
For puberty characterization, animals were grown in normalized litters (6-9 pups/litter). Estrous cyclicity was assessed in young adult virgin mice and after pregnancy and lactation. Fertility, latency to pregnancy, and the number of pups per litter were assessed in control and experimental mice.

Tissue collection and histology. Adult experimental and control male mice were deeply anesthetized with isoflurane (Fluriso, VetOne) and euthanized by decapitation. Blood from the trunk and peripheral tissues was quickly collected and immediately frozen in dry ice or liquid nitrogen. To assess deletion of specific gene targets and changes in transcript levels, a mouse brain matrix was used to obtain 1-mm frontal sections. A hypothalamic section at the level of the infundibulum/median eminence was used to dissect out a region containing the Arc, where LepR is highly expressed (69), by using a Palkovits punch (1.25 $\mathrm{mm}$ diameter) technique. Tissues were stored at $-80^{\circ} \mathrm{C}$ until RNA extraction was performed. Additionally, brains from adult male mice were collected after perfusion with $10 \%$ buffered formalin, and coronal sections were processed for ISH or IHC, as described below.

Leptin administration. Peripubertal $\mathrm{LR}^{\Delta \alpha}$ and control females were supplemented with i.p. saline or leptin $(2 \mu \mathrm{g} / \mathrm{g}$ of body weight per day, purchased from A.F. Parlow, Harbor-UCLA Medical Center, Torrance, California, USA, through the National Hormone and Peptide Program), from P35 to P55 ( $n=8-12 /$ treatment). To evaluate leptin sensitivity, the effect of leptin injection on food intake was evaluated in adult $\mathrm{LR}^{\Delta a}(n=8 /$ treatment$)$ and control ( $n=9 /$ treatment) male mice. Males of both genotypes were fasted for 24 hours and injected with i.p. leptin ( $5 \mu \mathrm{g} / \mathrm{g}$ of body weight) before lights off (at 6:00 PM) and were immediately refed. Food intake and body weight were measured after 3 hours of refeeding.

To assess leptin signaling and changes in transcript levels, $\mathrm{LR}^{\Delta \alpha}$ and control ( $n=6$ /group) male mice were fasted overnight and injected with i.p. saline or leptin $(2.5 \mu \mathrm{g} / \mathrm{g}$ of body weight $)$ at 11:00 AM; $30 \mathrm{~min}$ utes after injections, punches of the Arc were collected for qPCR analysis. For evaluation of leptin-induced phosphorylation of STAT3 and PTEN in the hypothalamus, diestrus LR ${ }^{\Delta \alpha}$ and control ( $n=8$ /group) mice were fasted overnight and injected with $2.5 \mu \mathrm{g} / \mathrm{g}$ of body weight of leptin at 11:00 AM; 30 minutes after i.p. leptin injection, the mediobasal hypothalamus $(\mathrm{MBH})$ was collected for protein analysis, as described below. For leptin-induced pAKT, MBHs from fasted diestrus $\mathrm{LR}^{\Delta \alpha}$ and control females were collected after 15 minutes of i.p. leptin injection.

Nutritional manipulation. Another cohort of $\mathrm{LR}^{\Delta \alpha}$ and control mice was used to assess the effect of postnatal overnutrition on the timing of puberty (31). At P1-P2, litter size was adjusted to produce mice in different nutritional states during postnatal development, i.e., overnutrition or small litter (SL: 2-4 pups/litter) and regular nutrition or normal litter (NL: 6-9 pups/litter). Body weight was monitored weekly after weaning, and vaginal lavages were collected starting at P32 to determine time of sexual maturation (first estrus) in control $\left(n=26 ; \alpha^{\mathrm{fl}}-\mathrm{NL}\right)$ and $\mathrm{LR}^{\Delta \alpha}\left(\mathrm{LR}^{\Delta \alpha}-\mathrm{NL}, n=12\right.$; and $\left.\mathrm{LR}^{\Delta \alpha}-\mathrm{SL}, n=13\right)$ mice. Additionally, serum samples for hormonal assay and ovaries were collected ( $n=6-10$ /group) from mice at P40. One cohort of adult $\mathrm{LR}^{\Delta \alpha}$ and control females was subjected to an obesogenic manipulation (HFD) for 15 weeks. Estrous cycle was assessed for 6 weeks, starting at week 7 of diet change ( $n=9-10$ /group).

Intracerebroventricular injection. Diestrus $\mathrm{LR}^{\Delta \alpha}$ and control females were fasted for 3 hours, anesthetized with isoflurane and mounted onto a stereotaxic apparatus (model 1900; Kopf Instruments) over a heating pad for implantation of a stainless-steel cannula into the right lateral ventricle (anteroposterior, $0.3 \mathrm{~mm}$; lateral, $1.0 \mathrm{~mm}$; and dorsoventral, $2.5 \mathrm{~mm}$ below the skull, relative to bregma). A single bolus injection of $12 \mu \mathrm{M}$ insulin or vehicle ( $3 \mu \mathrm{l})$ was injected, and mice were perfused after 15 minutes for brain collection and assessment of insulin signaling.

Glucose and insulin tolerance tests and hormone assays. For oral glucose tolerance test, adult $\mathrm{LR}^{\Delta \alpha+\beta}, \mathrm{LR}^{\Delta \alpha}$, and control males were fasted for 5 hours and received oral glucose $(2 \mathrm{~g} / \mathrm{kg})$ by gavage. Blood samples were collected prior to and after glucose gavage at times $0,15,30,60$, and 120 minutes via tail-vein bleeding. For insulin tolerance test, adult $\mathrm{LR}^{\Delta \alpha+\beta}$ and control mice were fasted for 5 hours and $1 \mathrm{U} / \mathrm{kg}$ insulin was given via i.p. injection. Blood was collected prior to and after insulin injection at times $0,15,30,60$, and 120 minutes via tail-vein bleeding. Glucose levels were measured using a glucometer (Accu-Check, Roche), and plasma insulin levels were determined using a rat/mouse insulin ELISA kit (Millipore). The limit of sensitivity of the assay was $0.2 \mathrm{ng} / \mathrm{ml}$, precision intraassay coefficient of variation (CV) was $8.35 \%$, and interassay CV was $17.9 \%$.

Blood samples were clotted for 45 minutes at room temperature and centrifuged for 15 minutes at $1,000 \mathrm{~g}$ at $4{ }^{\circ} \mathrm{C}$, and the serum was removed and stored at $-20^{\circ} \mathrm{C}$. Serum leptin levels were measured using the Millipore ELISA kit according to the manufacturer's instructions. The sensitivity of the leptin assay was $0.05 \mathrm{ng} / \mathrm{ml}$, and intraassay and interassay CV were $3.0 \%-4.6 \%$ and $1.1 \%-1.8 \%$, respectively. 
The sensitivity of the mouse IGF1 high sensitivity ELISA kit was $2.8 \mathrm{ng} / \mathrm{ml}$, and intraassay and interassay CV were $4.0 \%-6.8 \%$ and $6.2 \%-10.2 \%$, respectively. For LH assay, sera were sent to the University of Virginia Ligand Assay and Core of the Center for Research in Reproduction (Charlottesville, Virginia, USA), where serum LH was measured in a single assay by a 2-site LH sandwich RIA with sensitivity of $0.04 \mathrm{ng} / \mathrm{ml}$ and intraassay CV of $6.24 \%$.

IHC. Adult $\mathrm{LR}^{\Delta \alpha}$ and control (LR ${ }^{\mathrm{cre} / \mathrm{cre}}$ ) tdTomato mice were anesthetized by inhalation of isoflurane and were transcardially perfused with diethyl pyrocarbonate-treated (DEPC-treated) $0.1 \mathrm{M} \mathrm{PBS}$ and $10 \%$ buffered formalin for 10 minutes. Brains were dissected and kept in post-fixative ( $20 \%$ sucrose in fixative) for 2 hours and cryoprotected overnight in 20\% sucrose in DEPC-PBS. Brains were sectioned into $30-\mu \mathrm{m}$ coronal sections on a freezing microtome (Leica SM 2010R), divided in 4 series, and stored at $-20^{\circ} \mathrm{C}$ in DEPC-treated cryoprotectant. Brain sections were rinsed in PBS and blocked with 3\% normal donkey serum in PBS $+0.25 \%$ Triton-X 100 for 1 hour at room temperature. Sections were incubated overnight at $4^{\circ} \mathrm{C}$ with primary rabbit anti-AgRP (1:5,000, Phoenix Pharmaceuticals H-003-57), rabbit anti-phosphoAKT Ser473 (1:1,000, Cell Signaling Technologies, 4060), or rabbit anti-FoxO1 (1:1,000, Cell Signaling, 2880). Sections were rinsed and incubated with secondary donkey anti-rabbit IgG conjugated with fluorochrome Alexa Fluor 488 (Life Technologies) for 1.5 hour. The tdTomato red fluorescence is expressed specifically in LR cells of LepR-Cre mice and does not require additional immunostaining. Sections were mounted on gelatin-precoated slides and coverslipped with Fluoromont-G (Electron Microscopy Sciences) medium. Photomicrographs were acquired using Axio Imager M2 (Carl Zeiss) and Leica SP5 inverted 2-photon FLIM confocal microscopes. For quantification of pAKT/tdTomato and FoxO1/tdTomato cells and PVH AgRP projections, all images were acquired with same exposure time and images were quantified using ImageJ software (NIH, http://rsb.info.nih.gov/ij). Image-editing software (Adobe Photoshop CC) was used to integrate graphs and digital images into figures.

Dual-label ISH and IHC. Dual-label ISH and IHC were performed to determine the localization of

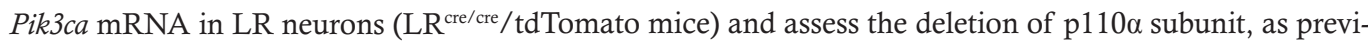
ously described (17). Briefly, free-floating sections from adult males $(n=4)$ were treated with $0.1 \%$ sodium borohydride for 15 minutes and with $0.25 \%$ acetic anhydride in DEPC-treated $0.1 \mathrm{M}$ triethanolamine $(\mathrm{pH}$ 8.0) for 10 minutes. Sections were incubated overnight at $50^{\circ} \mathrm{C}$ in hybridization solution $(50 \%$ formamide, $10 \mathrm{mM}$ Tris- $\mathrm{HCl}, \mathrm{pH} 8.0,5 \mathrm{mg}$ tRNA, $10 \mathrm{mM}$ dithiotreitol/DTT, $10 \%$ dextran sulfate, $0.3 \mathrm{M} \mathrm{NaCl}, 1$ mM EDTA, and $1 \times$ Denhardt's solution) containing the ${ }^{35}$ S-labeled Pik3ca riboprobe (17). Subsequently, sections were treated with RNase A for 30 minutes and submitted to stringency washes in sodium chloride-sodium citrate buffer. Sections were blocked in 3\% BSA (in PBS-Triton) and then incubated with a rabbit anti-dsRed (1:5,000; Clontech, 632496) antibody overnight at $4^{\circ} \mathrm{C}$. Sections were incubated for 1.5 hours in donkey anti-rabbit IgG-linked Alexa Fluor 594 (Alexa Fluor, Life Technologies) and were mounted onto SuperFrost plus slides, dehydrated in increasing concentrations of ethanol, dipped in NTB-2 autoradiographic emulsion (Kodak), dried, and stored in light-protected boxes at $4^{\circ} \mathrm{C}$ for 3 weeks. Slides were developed with D-19 developer (Kodak), dehydrated in graded ethanol, cleared in xylenes, and coverslipped with DPX mounting medium.

Microcomputed tomography. Dissected femora and lumbar vertebrae from females ( $n=6 /$ genotype) at $\mathrm{P} 60$ were immersed in PBS and stored at $-20^{\circ} \mathrm{C}$. Bones were scanned using a cone beam microtomographic imaging system (eXplore Locus SP, GE Healthcare Preclinical Imaging) to determine the tissue microarchitecture and densitometry. Scan parameters included an X-ray tube with a voltage of $80 \mathrm{kV}$, a current of $80 \mu \mathrm{A}$, and a 1,600-ms exposure time and a $0.508-\mathrm{mm}$ aluminum filter to reduce beam-hardening artifacts and a $0.7^{\circ}$ increment angle. All images were reconstructed at an $18-\mu \mathrm{m}$ isotropic voxel size and calibrated to a manufacturer-supplied phantom of air, water, and hydroxyapatite. MicroView v2.2 Advanced Bone Analysis Application (GE Healthcare Preclinical Imaging) software was employed for the reconstruction of the images. For trabecular measurements, regions of interest were placed proximal to the distal growth plate and spanned $10 \%$ of the entire length of the femur. Cortical regions of interest were placed at the middiaphysis and spanned $18 \%$ of the entire length of femur.

FACS. $\mathrm{LR}^{\text {cre/+ }}$ tdTomato (used as controls) and $\mathrm{LR}^{\text {cre/+ }}$ tdTomato $\mathrm{p} 110 \alpha$-floxed $\left(\mathrm{LR}^{\mathrm{cre} /+}-\alpha^{\mathrm{fl}}\right)$ mice were quickly decapitated and a MBH block was placed in a cold HBSS (Invitrogen). After a quick spin down, HBSS was replaced with $500 \mu \mathrm{l}$ of a $5 \%$ dispase solution in HBSS and incubated at $37^{\circ} \mathrm{C}$ for 15 minutes, with mechanical dissociation of the tissue by pipetting up and down. The addition of $500 \mu \mathrm{FACS}$ buffer $(2.2 \mathrm{ml} \mathrm{45 \%}$ tissue-culture grade D-glucose; $10 \mu 10.5 \mathrm{M}$ EDTA, pH 8.0, $30 \mathrm{mg}$ BSA in $10 \mathrm{ml}$ HBSS) 
was used to neutralize the dispase activity. The dissociated cells were pelleted at 2,000 $\mathrm{g}$ for 10 minutes at $4^{\circ} \mathrm{C}$. The supernatant was removed, and the pellet was dissolved in $500 \mu \mathrm{FACS}$ buffer and filtered in a cell-strainer topped polypropylene tube. Live neurons were collected in a cold Eppendorf tube containing $500 \mu \mathrm{l}$ of RNAlater solution (Ambion). The tubes were centrifuged at 5,000 $\mathrm{g}$ for 10 minutes at $4^{\circ} \mathrm{C}$, the excess RNAlater was removed, and the neurons were frozen at $-80^{\circ} \mathrm{C}$ until RNA extraction.

$q P C R$. Collected tissues were homogenized in Qiazol reagent (Qiagen), and total RNA was isolated using an RNA extraction kit (miRNeasy, Qiagen). cDNA was synthesized using a SuperScript II reverse transcriptase and random primers (Invitrogen) according to the manufacturer's protocols. Gene expression analyses were performed by qPCR using a CFX-384 Bio-Rad Real-Time PCR detection system in SYBR Green reaction. Changes in the expression of metabolic-related genes (i.e., Pomc, Agrp, Npy, Socs3, and Ucp1), class 1A PI3K-encoding genes (i.e., Pik3r1, Pik3r2, Pik3ca, Pik3cb, Pik3cd, and Pik3r4), and growth axis-related genes (Ghrh, Gh, Ghr, Sst, and $I g f 1$ ) were evaluated using specific oligo primers (Supplemental Table 2) purchased from IDT and MilliporeSigma. Gapdh expression was used as a housekeeping gene. The mRNA expression in mutant versus control mice was determined by a comparative cycle threshold method, and relative gene copy number was calculated as $2^{-\Delta \Delta \mathrm{Ct}}$ and presented as the percentage of the relative mRNA expression of the control group.

Western blotting. The $\mathrm{MBH}$ was dissected from an area about $1.0 \mathrm{~mm}$ lateral to the midline (optic tract as reference for lateral limit), at the anterior border of the optic chiasm and the anterior border of the mammillary bodies, and about $2.0 \mathrm{~mm}$ deep. Tissue was homogenized in 1\% Triton-X 100, $25 \mathrm{mM}$ Tris, pH 8.0, 1.5 mM EGTA, 0.5 mM EDTA, and protease inhibitor cocktail (PhosphoSTOP, Roche), and total protein was collected after centrifugation at $4^{\circ} \mathrm{C}$ and $15,000 \mathrm{~g}$ for 30 minutes. Aliquots of the lysates containing $25 \mu \mathrm{g}$ total protein were denatured in Laemmli buffer and $\beta$-mercaptoethanol (Bio-Rad) at $95^{\circ} \mathrm{C}$ for 5 minutes. Samples were separated by electrophoresis in SDS-PAGE and blotted onto a nitrocellulose membrane. Blots were blocked in 3\% BSA in Tris-buffered saline-Tween 20 (TBS-T) for 60 minutes at room temperature and incubated overnight with the following primary antibodies: rabbit anti-phosphoSTAT3 Tyr705 (1:2,000, Cell Signaling, 9131), mouse anti-STAT3 (1:1,000, Santa Cruz, 8019), anti-phospho-AKT Ser473 (1:3,000, Cell Signaling, 4060), rabbit anti-PTEN (1:3,000, Cell Signaling, 9188), or rabbit anti-GAPDH (1:4,000, Cell Signaling 5174). Membranes were rinsed in TBS-T and then incubated with horseradish peroxidase-linked anti-rabbit (1:4,000, Cell Signaling, 7074) or anti-mouse (1:4,000, Cell Signaling, 7076) IgG for 1 hour at room temperature. Chemiluminescent signal from antibody-antigen complexes was detected by Pierce ECL substrate (Thermo Scientific) and digital images were acquired in a ChemiDoc XRS+ system and analyzed with Image Lab software (Bio-Rad). Expression of pSTAT3 was normalized to STAT3 protein; PTEN levels were normalized to GAPDH protein; and pAKT was normalized to AKT protein. Data are presented as percentage of relative expression.

Statistics. Data are expressed as mean \pm SEM. Unpaired 2-tailed Student's $t$ test was used for comparison between 2 groups (e.g., control and $\mathrm{LR}^{\Delta \alpha}$ mice). When more than 2 independent variables were present in the analysis, 1-way ANOVA followed by Newman-Keuls post-hoc multiple comparison test was used. For analysis of effect of treatment and genotype, 2-way ANOVA followed by Tukey's post-hoc test was used. For analysis of effect of treatment and/or genotype in repeated-measures 2-way ANOVA followed by Holm-Sidak's multiple comparisons test was used. Statistical analysis was performed using GraphPad Prism v. 7 and SPSS v.20 softwares. A $P$ value of less than or equal to 0.05 was considered significant in all analyses. Group size estimations were based on similar studies published previously.

Study approval. All experiments were carried out in accordance with the guidelines established by the NIH's Guide for the Care and Use of Laboratory Animals (National Academies Press, 2011) and approved by the Institutional Animal Care and Use Committee of the University of Michigan (protocols 04380 and 06792).

\section{Author contributions}

DGG, BCB, and JD performed experiments and analyzed data. DGG, BCB, and NB acquired images and prepared data illustration. DGG, JWH, and CFE contributed to the study concept and experimental design. DGG, BCB, MW, and SJA produced the mouse colonies and genotyped the mice. JJZ developed the PI3K mouse models. KMK contributed to design and discussion of bone data. DGG and CFE supervised the project and wrote the manuscript. 


\section{Acknowledgments}

The University of Michigan Animal Phenotyping Core is supported by NIH P30 grants DK020572 (Michigan Diabetes Research Center) and DK089503 (Michigan Nutrition Obesity Research Center ). We thank the Ligand Core University of Virginia (National Centers for Translational Research in Reproduction and Infertility grant P50-HD28934), Basma Khoury for assistance in microcomputed tomography analysis, and Joel Elmquist for the critical review of the manuscript. This work was supported by the NIH (HD61539 and HD069702 to CFE), the São Paulo Research Foundation fellowship (FAPESP 2013/03915-0 to BCB), and The LALOR Foundation fellowship to DGG.

Address correspondence to: Carol F. Elias, 1137 E. Catherine Street, 7732B Medical Science Building II, Ann Arbor, Michigan 48109-5622, USA. Phone: 734.647.2801; Email: cfelias@umich.edu.

1. Foukas LC, et al. Critical role for the $\mathrm{p} 110 \alpha$ phosphoinositide-3-OH kinase in growth and metabolic regulation. Nature. 2006;441(7091):366-370.

2. Jia S, et al. Essential roles of PI(3)K-p110ß in cell growth, metabolism and tumorigenesis. Nature. 2008;454(7205):776-779.

3. Pal A, et al. PTEN mutations as a cause of constitutive insulin sensitivity and obesity. N Engl J Med. 2012;367(11):1002-1011.

4. Niswender KD, Morton GJ, Stearns WH, Rhodes CJ, Myers MG Jr, Schwartz MW. Intracellular signalling. Key enzyme in leptin-induced anorexia. Nature. 2001;413(6858):794-795.

5. Zhao AZ, Huan JN, Gupta S, Pal R, Sahu A. A phosphatidylinositol 3-kinase phosphodiesterase 3B-cyclic AMP pathway in hypothalamic action of leptin on feeding. Nat Neurosci. 2002;5(8):727-728.

6. Xu AW, Kaelin CB, Takeda K, Akira S, Schwartz MW, Barsh GS. PI3K integrates the action of insulin and leptin on hypothalamic neurons. J Clin Invest. 2005;115(4):951-958.

7. Morrison CD, Morton GJ, Niswender KD, Gelling RW, Schwartz MW. Leptin inhibits hypothalamic Npy and Agrp gene expression via a mechanism that requires phosphatidylinositol 3-OH-kinase signaling. Am J Physiol Endocrinol Metab. 2005;289(6):E1051-E1057.

8. Morton GJ, Gelling RW, Niswender KD, Morrison CD, Rhodes CJ, Schwartz MW. Leptin regulates insulin sensitivity via phosphatidylinositol-3-OH kinase signaling in mediobasal hypothalamic neurons. Cell Metab. 2005;2(6):411-420.

9. Vanhaesebroeck B, Ali K, Bilancio A, Geering B, Foukas LC. Signalling by PI3K isoforms: insights from gene-targeted mice. Trends Biochem Sci. 2005;30(4):194-204.

10. Bi L, Okabe I, Bernard DJ, Nussbaum RL. Early embryonic lethality in mice deficient in the p110 $\beta$ catalytic subunit of PI 3-kinase. Mamm Genome. 2002;13(3):169-172.

11. Ortega-Molina A, et al. Pten positively regulates brown adipose function, energy expenditure, and longevity. Cell Metab. 2012;15(3):382-394.

12. Foukas LC, et al. Long-term p110ß PI3K inactivation exerts a beneficial effect on metabolism. EMBO Mol Med. 2013;5(4):563-571.

13. Ortega-Molina A, et al. Pharmacological inhibition of PI3K reduces adiposity and metabolic syndrome in obese mice and rhesus monkeys. Cell Metab. 2015;21(4):558-570

14. Plum L, et al. Enhanced leptin-stimulated Pi3k activation in the CNS promotes white adipose tissue transdifferentiation. Cell Metab. 2007;6(6):431-445.

15. Hill JW, et al. Direct insulin and leptin action on pro-opiomelanocortin neurons is required for normal glucose homeostasis and fertility. Cell Metab. 2010;11(4):286-297.

16. Xu Y, et al. PI3K signaling in the ventromedial hypothalamic nucleus is required for normal energy homeostasis. Cell Metab. 2010;12(1):88-95.

17. Williams KW, et al. The acute effects of leptin require PI3K signaling in the hypothalamic ventral premammillary nucleus. $J$ Neurosci. 2011;31(37):13147-13156.

18. Klöckener T, et al. High-fat feeding promotes obesity via insulin receptor/PI3K-dependent inhibition of SF-1 VMH neurons. Nat Neurosci. 2011;14(7):911-918.

19. Sohn JW, Oh Y, Kim KW, Lee S, Williams KW, Elmquist JK. Leptin and insulin engage specific PI3K subunits in hypothalamic SF1 neurons. Mol Metab. 2016;5(8):669-679.

20. Hill JW, et al. Acute effects of leptin require PI3K signaling in hypothalamic proopiomelanocortin neurons in mice. J Clin Invest 2008;118(5):1796-1805.

21. Al-Qassab H, et al. Dominant role of the $\mathrm{p} 110 \beta$ isoform of PI3K over $\mathrm{p} 110 \alpha$ in energy homeostasis regulation by POMC and AgRP neurons. Cell Metab. 2009;10(5):343-354.

22. Hill JW, et al. Phosphatidyl inositol 3-kinase signaling in hypothalamic proopiomelanocortin neurons contributes to the regulation of glucose homeostasis. Endocrinology. 2009;150(11):4874-4882.

23. Bates $\mathrm{SH}$, et al. STAT3 signalling is required for leptin regulation of energy balance but not reproduction. Nature. 2003;421(6925):856-859.

24. Björnholm M, et al. Mice lacking inhibitory leptin receptor signals are lean with normal endocrine function. J Clin Invest. 2007;117(5):1354-1360.

25. Patterson CM, et al. Leptin action via LepR-b Tyr1077 contributes to the control of energy balance and female reproduction. Mol Metab. 2012;1(1-2):61-69.

26. Singireddy AV, Inglis MA, Zuure WA, Kim JS, Anderson GM. Neither signal transducer and activator of transcription 3 (STAT3) or STAT5 signaling pathways are required for leptin's effects on fertility in mice. Endocrinology. 2013;154(7):2434-2445.

27. Borges BC, Garcia-Galiano D, Rorato R, Elias LL, Elias CF. PI3K p110 $\beta$ subunit in leptin receptor expressing cells is required for the acute hypophagia induced by endotoxemia. Mol Metab. 2016;5(6):379-391. 
28. Kennedy GC, Mitra J. Body weight and food intake as initiating factors for puberty in the rat. J Physiol (Lond). 1963;166:408-418. 29. Elias CF, Purohit D. Leptin signaling and circuits in puberty and fertility. Cell Mol Life Sci. 2013;70(5):841-862.

30. Castellano JM, et al. Early metabolic programming of puberty onset: impact of changes in postnatal feeding and rearing conditions on the timing of puberty and development of the hypothalamic kisspeptin system. Endocrinology. 2011;152(9):3396-3408.

31. Caron E, Ciofi P, Prevot V, Bouret SG. Alteration in neonatal nutrition causes perturbations in hypothalamic neural circuits controlling reproductive function. J Neurosci. 2012;32(33):11486-11494.

32. Brothers KJ, et al. Rescue of obesity-induced infertility in female mice due to a pituitary-specific knockout of the insulin receptor. Cell Metab. 2010;12(3):295-305.

33. Short RV. Lactation — the central control of reproduction. Ciba Found Symp. 1976;(45):73-86.

34. McNeilly AS. Effects of lactation on fertility. Br Med Bull. 1979;35(2):151-154

35. Brachmann SM, Ueki K, Engelman JA, Kahn RC, Cantley LC. Phosphoinositide 3-kinase catalytic subunit deletion and regulatory subunit deletion have opposite effects on insulin sensitivity in mice. Mol Cell Biol. 2005;25(5):1596-1607.

36. Williams KW, et al. Segregation of acute leptin and insulin effects in distinct populations of arcuate proopiomelanocortin neurons. J Neurosci. 2010;30(7):2472-2479.

37. Koch C, et al. Leptin rapidly improves glucose homeostasis in obese mice by increasing hypothalamic insulin sensitivity. $J$ Neurosci. 2010;30(48):16180-16187.

38. Qiu X, et al. Delayed puberty but normal fertility in mice with selective deletion of insulin receptors from Kiss1 cells. Endocrinol ogy. 2013;154(3):1337-1348.

39. Lam DD, Attard CA, Mercer AJ, Myers MG Jr, Rubinstein M, Low MJ. Conditional expression of Pomc in the Lepr-positive subpopulation of POMC neurons is sufficient for normal energy homeostasis and metabolism. Endocrinology. 2015;156(4):1292-1302.

40. Tsou RC, Bence KK. Central regulation of metabolism by protein tyrosine phosphatases. Front Neurosci. 2012;6:192.

41. Onweluzo JC, Leelavathi K, Rao PH. Effect of Detarium microcarpum (Dm) and Mucuna flagellipes (Mf) gums on the quality of white bread. Plant Foods Hum Nutr. 1999;54(2):173-182.

42. Ducy P, et al. Leptin inhibits bone formation through a hypothalamic relay: a central control of bone mass. Cell. 2000;100(2):197-207.

43. Sasanuma H, Nakata M, Parmila K, Nakae J, Yada T. PDK1-FoxO1 pathway in AgRP neurons of arcuate nucleus promotes bone formation via GHRH-GH-IGF1 axis. Mol Metab. 2017;6(5):428-439.

44. Ahima RS, et al. Role of leptin in the neuroendocrine response to fasting. Nature. 1996;382(6588):250-252.

45. Welt CK, et al. Recombinant human leptin in women with hypothalamic amenorrhea. N Engl J Med. 2004;351(10):987-997.

46. Ahima RS, Dushay J, Flier SN, Prabakaran D, Flier JS. Leptin accelerates the onset of puberty in normal female mice. JClin Invest. 1997;99(3):391-395.

47. Tena-Sempere M, et al. Molecular mechanisms of leptin action in adult rat testis: potential targets for leptin-induced inhibition of steroidogenesis and pattern of leptin receptor messenger ribonucleic acid expression. J Endocrinol. 2001;170(2):413-423.

48. Cohen P, et al. Selective deletion of leptin receptor in neurons leads to obesity. J Clin Invest. 2001;108(8):1113-1121.

49. de Luca C, et al. Complete rescue of obesity, diabetes, and infertility in $\mathrm{db} / \mathrm{db}$ mice by neuron-specific LEPR-B transgenes. $J$ Clin Invest. 2005;115(12):3484-3493.

50. Donato J Jr, et al. Leptin's effect on puberty in mice is relayed by the ventral premammillary nucleus and does not require signaling in Kiss1 neurons. J Clin Invest. 2011;121(1):355-368.

51. Wu Q, Whiddon BB, Palmiter RD. Ablation of neurons expressing agouti-related protein, but not melanin concentrating hormone, in leptin-deficient mice restores metabolic functions and fertility. Proc Natl Acad Sci U S A. 2012;109(8):3155-3160.

52. Sheffer-Babila S, Sun Y, Israel DD, Liu SM, Neal-Perry G, Chua SC. Agouti-related peptide plays a critical role in leptin's effects on female puberty and reproduction. Am J Physiol Endocrinol Metab. 2013;305(12):E1512-E1520.

53. Egan OK, Inglis MA, Anderson GM. Leptin signaling in AgRP neurons modulates puberty onset and adult fertility in mice. $J$ Neurosci. 2017;37(14):3875-3886

54. Wilding JP, et al. Increased neuropeptide-Y messenger ribonucleic acid (mRNA) and decreased neurotensin mRNA in the hypothalamus of the obese (ob/ob) mouse. Endocrinology. 1993;132(5):1939-1944.

55. Schwartz MW, Seeley RJ, Campfield LA, Burn P, Baskin DG. Identification of targets of leptin action in rat hypothalamus. $J$ Clin Invest. 1996;98(5):1101-1106.

56. Elias CF, et al. Leptin differentially regulates NPY and POMC neurons projecting to the lateral hypothalamic area. Neuron. 1999;23(4):775-786.

57. Ueki K, et al. Positive and negative roles of $\mathrm{p} 85 \alpha$ and $\mathrm{p} 85 \beta$ regulatory subunits of phosphoinositide 3 -kinase in insulin signaling J Biol Chem. 2003;278(48):48453-48466.

58. Ueki K, et al. Increased insulin sensitivity in mice lacking p $85 \beta$ subunit of phosphoinositide 3-kinase. Proc Natl Acad Sci U S A. 2002;99(1):419-424.

59. Vanhaesebroeck B, Guillermet-Guibert J, Graupera M, Bilanges B. The emerging mechanisms of isoform-specific PI3K signalling. Nat Rev Mol Cell Biol. 2010;11(5):329-341.

60. Fruman DA, et al. Hypoglycaemia, liver necrosis and perinatal death in mice lacking all isoforms of phosphoinositide 3-kinase p85a. Nat Genet. 2000;26(3):379-382.

61. Day FR, et al. Genomic analyses identify hundreds of variants associated with age at menarche and support a role for puberty timing in cancer risk. Nat Genet. 2017;49(6):834-841.

62. Rodon J, Dienstmann R, Serra V, Tabernero J. Development of PI3K inhibitors: lessons learned from early clinical trials. Nat Rev Clin Oncol. 2013;10(3):143-153.

63. DeFalco J, et al. Virus-assisted mapping of neural inputs to a feeding center in the hypothalamus. Science. 2001;291(5513):2608-2613.

64. Zhao JJ, et al. The $\mathrm{p} 110 \alpha$ isoform of PI3K is essential for proper growth factor signaling and oncogenic transformation. Proc Natl Acad Sci U S A. 2006;103(44):16296-16300.

65. Brüning JC, et al. A muscle-specific insulin receptor knockout exhibits features of the metabolic syndrome of NIDDM without altering glucose tolerance. Mol Cell. 1998;2(5):559-569.

66. Madisen L, et al. A robust and high-throughput Cre reporting and characterization system for the whole mouse brain. Nat Neu- 
rosci. 2010;13(1):133-140.

67. Vandenbergh JG, Whitsett JM, Lombardi JR. Partial isolation of a pheromone accelerating puberty in female mice. J Reprod Fertil. 1975;43(3):515-523.

68. Leshan RL, Louis GW, Jo YH, Rhodes CJ, Münzberg H, Myers MG. Direct innervation of GnRH neurons by metabolic- and sexual odorant-sensing leptin receptor neurons in the hypothalamic ventral premammillary nucleus. J Neurosci. 2009;29(10):3138-3147.

69. Scott MM, et al. Leptin targets in the mouse brain. J Comp Neurol. 2009;514(5):518-532.

70. García-Galiano D, et al. Kisspeptin signaling is indispensable for neurokinin B, but not glutamate, stimulation of gonadotropin secretion in mice. Endocrinology. 2012;153(1):316-328.

71. Torsoni MA, et al. AMPK $\alpha 2$ in Kiss 1 neurons is required for reproductive adaptations to acute metabolic challenges in adult female mice. Endocrinology. 2016;157(12):4803-4816. 